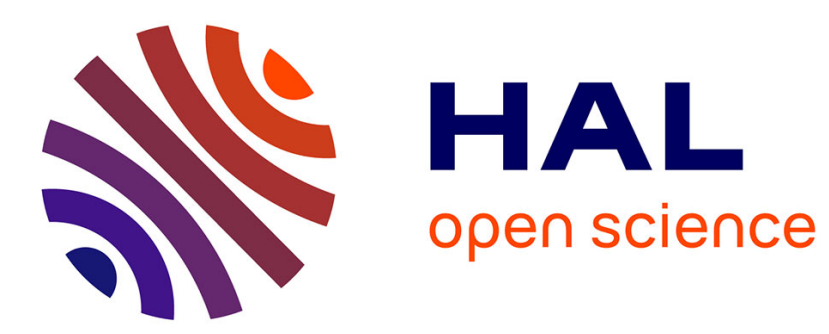

\title{
Thermal oxidation of Poly(dicyclopentadiene)- kinetic modeling of double bond consumption
}

Jing Huang, Adelina David, Pierre-Yves Le Gac, Cédric Lorthioir, Cristina Coelho, Emmanuel Richaud

\section{- To cite this version:}

Jing Huang, Adelina David, Pierre-Yves Le Gac, Cédric Lorthioir, Cristina Coelho, et al.. Thermal oxidation of Poly(dicyclopentadiene)- kinetic modeling of double bond consumption. Polymer Degradation and Stability, 2019, 166, pp.258-271. 10.1016/j.polymdegradstab.2019.06.003 . hal-02178895

\section{HAL Id: hal-02178895 \\ https://hal.science/hal-02178895}

Submitted on 10 Jul 2019

HAL is a multi-disciplinary open access archive for the deposit and dissemination of scientific research documents, whether they are published or not. The documents may come from teaching and research institutions in France or abroad, or from public or private research centers.
L'archive ouverte pluridisciplinaire HAL, est destinée au dépôt et à la diffusion de documents scientifiques de niveau recherche, publiés ou non, émanant des établissements d'enseignement et de recherche français ou étrangers, des laboratoires publics ou privés. 


\title{
Thermal oxidation of Poly(dicyclopentadiene)- kinetic modeling of double bond consumption
}

\author{
Jing Huang a, Adelina David ${ }^{\mathrm{b}}$, Pierre-Yves Le Gac ${ }^{\mathrm{b}}$, Cedric Lorthioir ${ }^{\mathrm{c}}$, Cristina Coelho ${ }^{\mathrm{d}}$, \\ Emmanuel Richaud ${ }^{\text {a, * }}$ \\ a Laboratoire PIMM, Arts et Métiers, CNRS, Cnam, HESAM Université, 151 Boulevard de l'Hôpital, F-75013, Paris, France \\ ${ }^{\mathrm{b}}$ IFREMER, Service Matériaux et Structures, Centre de Brest BP70, F-29280, Plouzané, France \\ ' Sorbonne Université, CNRS, Collège de France, Laboratoire de Chimie de la Matière Condensée de Paris, LCMCP, 4 Place Jussieu, F-75005, Paris, France \\ d Sorbonne Université, CNRS, Institut des Matériaux de Paris Centre, FR 2482, F-75005, Paris, France
}

\begin{abstract}
A B S T R A C T
This paper reports chemical changes that occur in polydicyclopentadiene during thermal oxidation at several temperatures and oxygen pressures. A particular attention was paid to the double bond consumption since these latter are associated with crosslinking and subsequent changes in mechanical properties. A kinetic model was derived from the experimental results. Its rate constants were assessed from the "inverse approach" based on their selective identification under specific ageing conditions (for example under oxygen excess). The resulting model satisfactorily describes both carbonyl formation and double bond consumption for a wide range of temperature and oxygen pressure for the first time. This can be exploited to predict the changes of local mechanical properties.
\end{abstract}

\section{Introduction}

Polydicyclopentadiene (PDCPD) is obtained by metathesis of dicyclopentadiene, as illustrated in Fig. 1. This polymerization mechanism (for which the Nobel Prize in Chemistry was awarded to Chauvin, Grubbs and Schrock in 2005 [1,2]) presents several interests, especially the possibility to prepare a bulk material from a low-viscosity reactive mixture in a short processing time (ca $1 \mathrm{~min}$ ), without the requirement of external heating. The specificity of this polymerization mechanism is to keep the concentration of double bonds almost unchanged compared to the monomer.

It is well established [3] that the mechanical properties of thermoset polymers depend on:

- cohesive properties (for elastic modulus) which can change during oxidation due to the appearance of new chemical groups (ketones, carboxylic acids ...),

- sub-glassy mobility (not always evidenced in PDCPD) for toughness,

\footnotetext{
* Corresponding author.

E-mail address: emmanuel.richaud@ensam.eu (E. Richaud).
}

- crosslink density (for glass transition and yield properties) which can change with crosslinking or chain scissions.

Many authors have emphasized the effects of thermal oxidation [4] and crosslinking [5] on physical and mechanical properties through experiments (e.g. $T_{g}$, rubbery modulus, tensile properties). A recent article [6] reported that the oxidation of PDCPD induces an increase of the rubbery modulus which indicates an oxidation induced crosslinking process. Several reactions can be considered to explain this behavior since both alkyl radicals $\left(\mathrm{P}^{\circ}\right)$ and peroxy radicals $\left(\mathrm{POO}^{\circ}\right)$ are very reactive and can participate in the coupling between two radicals by a termination process or the reaction with a double bond in a similar way to elastomer oxidation [7].

A reliable lifetime prediction of PDCPD thus requires an accurate description of crosslink density during oxidation. In this contribution, our aim is to monitor the chemical modifications involved in PDCPD crosslinking during its thermal oxidation. Such information will allow a better understanding of the interplay with the variations of the mechanical behavior observed for aged polymers. For this purpose, we will complete the previously established kinetic model [8] by considering reactions involving the PDCPD double bonds and determining their rate constants. Since crosslinking and double bond consumption can originate from reactions with either 

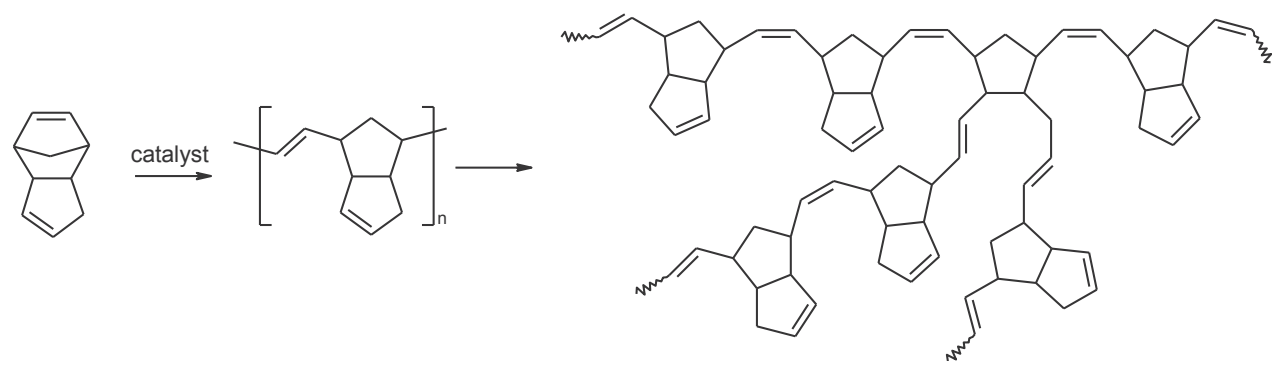

Fig. 1. Polymerization of polydicyclopentadiene.

$\mathrm{P}^{\circ}$ or $\mathrm{POO}^{\circ}$ species, our strategy relies on the comparison of the aging behavior under air and under different oxygen pressures $[9,10]$ (which is a way to isolate the specific contribution of some rate constants) following a similar approach to the one used previously for polybutadiene [11] and polychloroprene [12]. Such an experimental approach should help achieve a better separation of the contributions from these two types of reactions. To facilitate this resolution, some approximated analytical calculations, that are intended to orientate the numerical solution, will first be carried out. The extent of agreement between both numerical simulations and analytical solutions will be considered.

\section{Experimental}

\subsection{Material}

The poly(dicyclopentadiene) samples under investigation (Telene 1810 , Telene SAS) were supplied as a stabilized bulk material prepared by reaction injection molding process (RIM) at about $40^{\circ} \mathrm{C}$. The catalyst used for the metathesis polymerization is a ruthenium salicylaldimine phenylindenylidene complex. By cutting the bulk material with a microtome (RM 2255 Leica), films having a thickness lower than $10 \mu \mathrm{m}$ were obtained and these were then purified by refluxing in $\mathrm{CH}_{2} \mathrm{Cl}_{2}$ (ref $270997 \geq 99.8 \%$, Sigma-Aldrich) overnight. It is important to note that this thickness is low enough to avoid the Diffusion-Limited Oxidation effects [13]. Unstabilized samples were stored at $-20^{\circ} \mathrm{C}$ before ageing.

96\% cyclopentene (ref 344508 96\%, Sigma-Aldrich), cis-1,4polybutadiene (ref 181374 Sigma-Aldrich) and polybutadiene (ref 181382 Sigma-Aldrich) were used as model (macro)molecules. The cis-1,4, trans-1,4, and vinyl-1,2 unit contents of both homopolymers of polybutadiene (from supplier data) are provided in Table 1.

\subsection{Exposure conditions}

Two distinct kinds of exposure conditions are considered in this study. Samples were exposed at various temperatures $\left(30^{\circ} \mathrm{C}, 50^{\circ} \mathrm{C}\right.$, $70^{\circ} \mathrm{C}$ ), either in air-ventilated ovens at atmospheric pressure or in autoclaves at different oxygen pressures between $0.2 \mathrm{MPa}$ and $1 \mathrm{MPa}$. Exposures at $20^{\circ} \mathrm{C}$ were performed in air-conditioned room of the lab.

Table 1

The microstructure of the polybutadiene homopolymers considered.

\begin{tabular}{llll}
\hline Sample & \multicolumn{2}{l}{ Microstructure (\%) } & \\
\cline { 2 - 4 } & cis-1,4 & trans-1,4 & vinyl-1,2 \\
\hline PB1 & 98 & 55 & 2 \\
PB2 & 36 & 55 & 9 \\
\hline
\end{tabular}

\subsection{Preparation and characterization}

\subsubsection{Fourier transform InfraRed spectroscopy}

The FTIR spectra were collected on a Frontier spectrometer (PerkinElmer), as the average of 4 scans performed over a spectral range from 400 to $4000 \mathrm{~cm}^{-1}$, with a resolution of $4 \mathrm{~cm}^{-1}$. Spectra were then analyzed with Spectrum ${ }^{\mathrm{TM}}$ software.

The concentrations of carbonyls generated by oxidation were calculated using the Beer-Lambert equation with a molar absorptivity of $300 \mathrm{moll}^{-1} \mathrm{~cm}^{-1}$ [4] at $1710 \mathrm{~cm}^{-1}$. The double bond concentration methods will be detailed later.

To better assess this latter, some comparisons were made with:

- Cyclopentene: a few drops were placed on a $\mathrm{KBr}$ window with an optical path of $0.05 \mathrm{~mm}$ (ref 1921 supplied by Eurolabo) to verify the assignment of the absorption bands from the carboncarbon double bonds and to calculate their molar absorptivities.

- Polybutadienes casted on a $\mathrm{KBr}$ disk from a chloroform solution. The analyses, performed after complete solvent evaporation, aimed at verifying the assignment of the absorption bands from the carbon-carbon double bonds.

\subsubsection{Differential scanning calorimetry}

The hydroperoxide concentration was measured using a Q10 DSC calorimeter (TA Instrument) driven by Q Series Explorer ${ }^{\mathrm{TM}}$ software $[14,15]$. Temperature and enthalpy calibrations were first calibrated with an indium standard. Approximately $0.3 \mathrm{mg}$ of virgin or oxidized samples were heated from 20 to $300^{\circ} \mathrm{C}$, at a heating rate of $10^{\circ} \mathrm{C} \mathrm{min}{ }^{-1}$ in a sealed aluminium pan. This heating procedure was performed under an inert atmosphere obtained using nitrogen as a purge gas at a flow rate of $50 \mathrm{ml} \mathrm{min}^{-1}$. Results were processed using the TA Analysis software. The values of exotherms ascribed to hydroperoxides were converted into concentrations using $\Delta \mathrm{H}=440 \mathrm{~kJ} \mathrm{~mol}^{-1}[8]$.

\subsection{3. $\mathrm{SO}_{2}$ treatment}

Degraded samples $(5 \mathrm{mg})$ were placed in closed vessels and immersed in solutions of $5 \mathrm{mg}$ of $\mathrm{Na}_{2} \mathrm{SO}_{3}$ (ref 71988 Sigma Aldrich) in $10 \mathrm{ml} \mathrm{HCl}$ (ref 40253 Sigma Aldrich, $37 \mathrm{wt} \%$ in $\mathrm{H}_{2} \mathrm{O}$ ) in which $\mathrm{SO}_{2}$ was generated in situ for $24 \mathrm{~h}$ at room temperature [14].

\subsubsection{Solid-state NMR}

${ }^{1} \mathrm{H}$ solid-state NMR spectroscopy was used to determine the carbon-carbon double bond concentration. The NMR measurements were performed on a Bruker Avance III NMR spectrometer operating at a ${ }^{1} \mathrm{H}$ Larmor frequency of $700.14 \mathrm{MHz}$, equipped with an ultrafast MAS $1.3 \mathrm{~mm}$ double-resonance ${ }^{1} \mathrm{H}-\mathrm{X}$ probe spinning up to $67 \mathrm{kHz} .{ }^{1} \mathrm{H}$ one-pulse experiments were carried out with a $90^{\circ}\left({ }^{1} \mathrm{H}\right)$ pulse length of $2.0 \mu$ s and the recycle delay was varied between $20 \mathrm{~s}$ and $120 \mathrm{~s}$, depending on the $\mathrm{T}_{1}\left({ }^{1} \mathrm{H}\right)$ relaxation. The ${ }^{1} \mathrm{H}$ 
chemical shift values were referenced using adamantane as an external reference (1.91 ppm with respect to TMS).

\subsubsection{Tensile tests}

Tensile tests were performed using $60 \mu \mathrm{m}$ thick samples in order to obtain homogeneous oxidation through the sample thickness. Samples were cut in a dogbone shape with an initial working length of $10 \mathrm{~mm}$. They were tested after several ageing durations at $80^{\circ} \mathrm{C}$ in air using an Instron test machine with a $50 \mathrm{~N}$ load cell and strain measured by Digital Image Correlation. For each condition, at least 8 samples were characterized in order to ensure reliability of results.

\section{Results}

\subsection{Detection and quantification of hydroperoxides}

The changes in chemical structures of PDCPD exposed at $50^{\circ} \mathrm{C}$ under air were monitored by FTIR spectroscopy. An increase of the absorption band at ca $3400 \mathrm{~cm}^{-1}$, corresponding to hydrogen- bonded hydroxyl groups, is observed on Fig. 2a. This broad band results from various species such as hydroperoxides, alcohols or carboxylic acids, all of which are oxidation products occurring in the thermal oxidation of other hydrocarbon polymers [14]. It is however difficult to distinguish these different species basing on the FTIR data.

Hydroperoxides, which are the key species of the oxidation mechanism, can also be selectively detected and quantified by other chemical or thermal methods [14]. The DSC traces of PDCDP samples oxidized at $70^{\circ} \mathrm{C}$ (Fig. 3a) show that the enthalpy change for the exotherm centered at about $150{ }^{\circ} \mathrm{C}$ increases with the exposure time. Moreover, this exotherm disappears upon treatment by sulfur dioxide. It is noteworthy that no residual exotherm was detected after $\mathrm{SO}_{2}$ treatment for several PDCPD samples subjected to thermal oxidation at varying temperatures (50 and $70^{\circ} \mathrm{C}$ ) and times corresponding to the maximal enthalpy release $\left(10 \mathrm{~h}\right.$ at $50^{\circ} \mathrm{C}$ and $4 \mathrm{~h}$ at $\left.70^{\circ} \mathrm{C}\right)$.

This exotherm is hence attributed to the decomposition of hydroperoxides $(\mathrm{POOH})$ depicted in Fig. 4, the formation of which results from the propagation step schematized in Scheme 1.

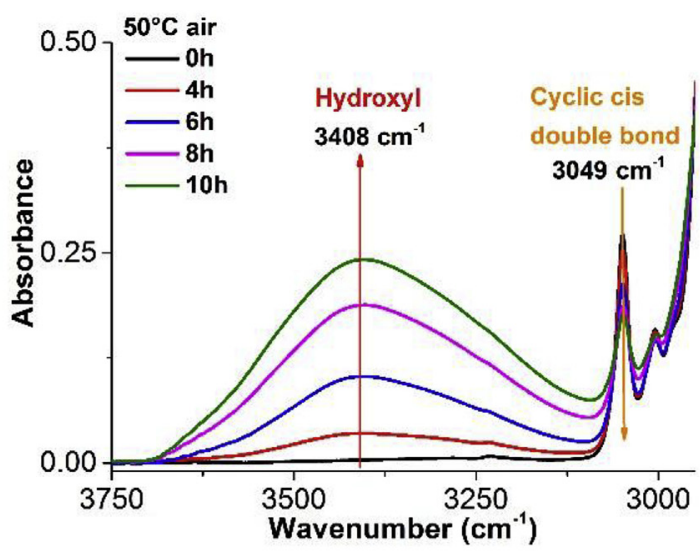

(a)

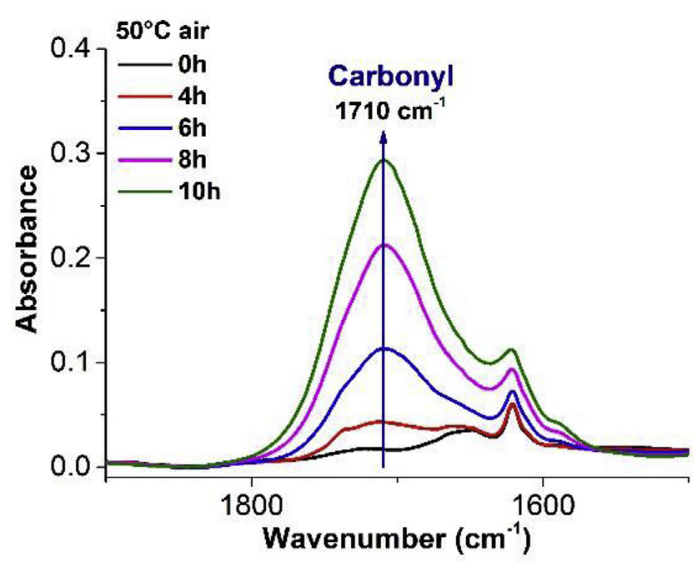

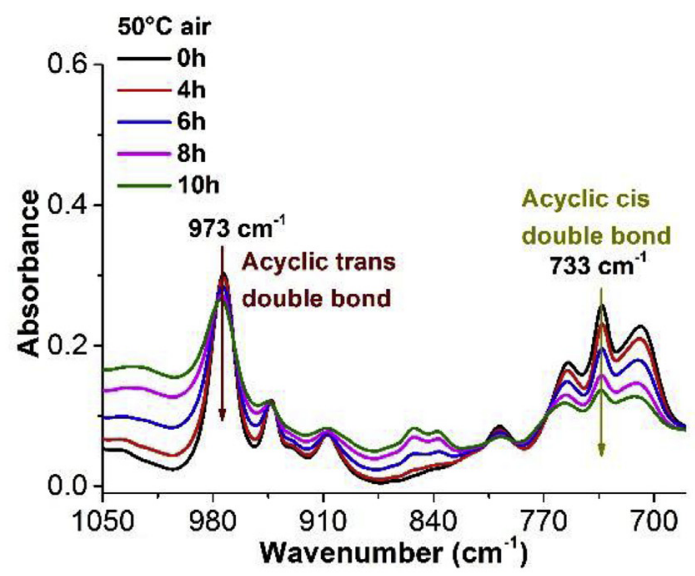

(b)

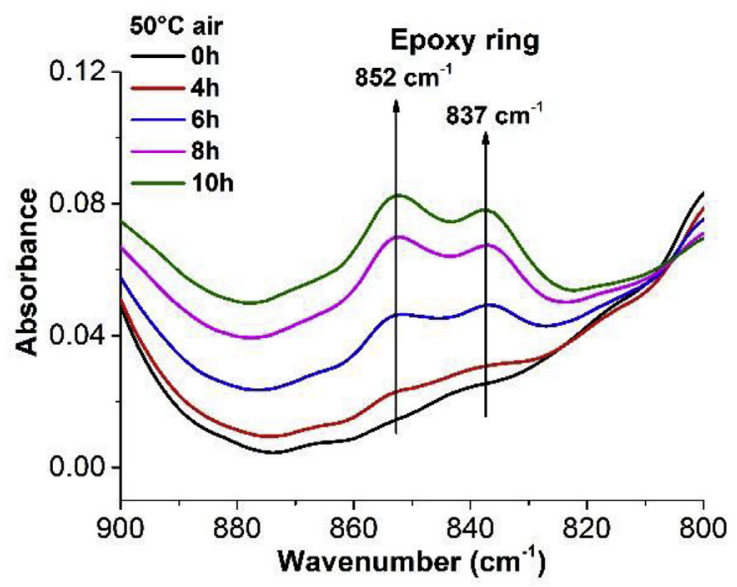

Fig. 2. Changes in the FTIR spectra of PDCPD exposed at $50^{\circ} \mathrm{C}$ in air. 


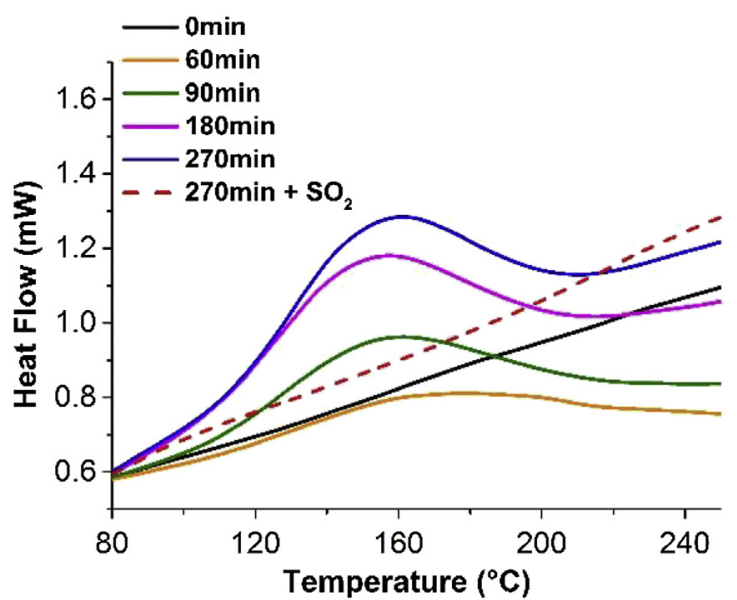

(a)

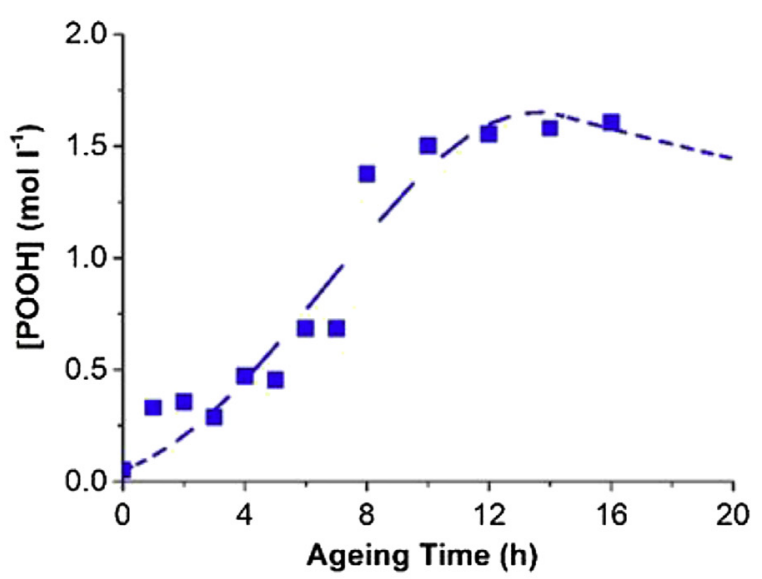

(b)

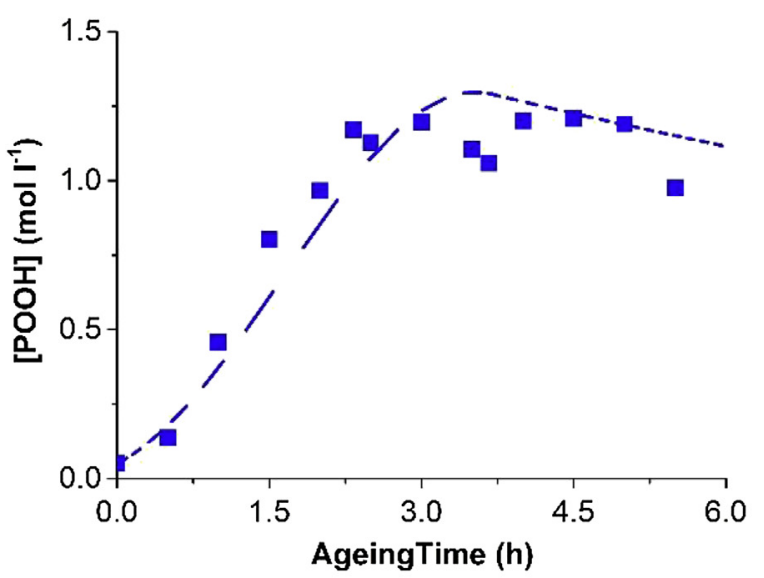

(c)

Fig. 3. DSC thermograms for purified PDCPD samples before oxidation (-), and after oxidation for various exposure times at $70^{\circ} \mathrm{C}$, followed by $\mathrm{SO}_{2}$ treatment $(-)(\mathrm{a})$; Changes in hydroperoxide concentration with the ageing time measured by DSC ( $\mathbf{\square}$ and simulation runs (--) at $50^{\circ} \mathrm{C}(\mathrm{b})$ and at $70^{\circ} \mathrm{C}(\mathrm{c})$.

It should be noted that several kinds of hydroperoxides can actually be formed (Fig. 4). The relative probability of each kind of hydroperoxide (depending at least on bond dissociation of the $\mathrm{C}-\mathrm{H}$ precursor, and hindrance) will not be discussed here.

The $\mathrm{POOH}$ concentration was assessed from the value of the exotherm. Fig. $3 \mathrm{~b}$ shows, for $50^{\circ} \mathrm{C}$ and in Fig. $3 \mathrm{c}$ for $70^{\circ} \mathrm{C}$, the growth curve of hydroperoxides as a function of the aging time, which has been confirmed experimentally by other authors [16].

\subsection{Concentration of double bonds}

\section{(1) In virgin PDCPD}

Since the concentration of double bonds in the unaged PDCPD is needed in order to propose a kinetic model, FTIR experiments were first used to determine this quantity. The assignment of characteristic absorption bands for double bonds, reported in Fig. 2a and $\mathrm{b}$, has been verified using model molecules (cyclopentene and polybutadiene homopolymers, Fig. 5) and was found to be in agreement with the literature. More precisely, the peak at $3049 \mathrm{~cm}^{-1}$ (Fig. 2a) is attributed to $\omega(=\mathrm{C}-\mathrm{H})$ for cyclic cis double bonds, as confirmed by the FTIR spectrum of cyclopentene (Fig. 5a) $[17,18]$. The peak at $973 \mathrm{~cm}^{-1}$ is related to $\omega(=\mathrm{C}-\mathrm{H})$ for acyclic trans double bonds, as also observed for a polybutadiene homopolymer with $55 \%$ of trans-1,4 units (Fig. 5b) [17,19,20].

The cis $=\mathrm{C}-\mathrm{H}$ wagging bands for cis dialkyl ethylenes are located in the $720-680 \mathrm{~cm}^{-1}$ region, even though this band is less dependable for structural elucidation [20]. Two peaks may be observed on the FTIR spectrum of PDCPD near this range, at 733 and $709 \mathrm{~cm}^{-1}$ (Fig. 5c). Nava and al [19]. proved that polybutadienes differing by their 1,2 vinyl, 1,4 cis and 1,4 trans content always display a medium-strong band in the $728-750 \mathrm{~cm}^{-1}$ region corresponding to cis $\omega(=\mathrm{C}-\mathrm{H})$ so that the band at $733 \mathrm{~cm}^{-1}$ is attributed to acyclic cis double bonds [3].

The total double bond concentration within PDCPD is the sum of three contributions corresponding to cyclic cis $-\mathrm{HC}=\mathrm{CH}$ - bonds, acyclic cis $-\mathrm{HC}=\mathrm{CH}$ - bonds and acyclic trans $-\mathrm{HC}=\mathrm{CH}$ - bonds:

$$
\begin{aligned}
{[C} & =C]=[C=C]_{\text {cyclic cis double bond }}+[C=C]_{\text {acyclic cis double bond }} \\
& +[C=C]_{\text {acyclic trans double bond }}
\end{aligned}
$$

Using values of molar absorptivity equal to $191 \mathrm{~mol}^{-1} \mathrm{~cm}^{-1}$ for cyclic cis $-\mathrm{H}=\mathrm{C}, 601 \mathrm{~mol}^{-1} \mathrm{~cm}^{-1}$ for cis vinylene units $(\mathrm{R}-\mathrm{CH}=\mathrm{CH}-$ $\mathrm{R}^{\prime}$ ) [21], and $1001 \mathrm{~mol}^{-1} \mathrm{~cm}^{-1}$ for trans vinylene units ( $\mathrm{R}-\mathrm{CH}=\mathrm{CH}-$ $\left.\mathrm{R}^{\prime}\right)$ [22], this concentration can be expressed as:

$$
\begin{aligned}
{[C} & =C]=\frac{[=C-H]_{3049}}{2}+\frac{[=C-H]_{973}}{2}+\frac{[=C-H]_{733}}{2} \\
& =\frac{1}{2} \times \frac{1}{l} \times\left(\frac{A_{3049}}{\varepsilon_{3049}}+\frac{A_{733}}{\varepsilon_{733}}+\frac{A_{973}}{\varepsilon_{973}}\right)
\end{aligned}
$$

As a result, the double bond concentration of purified, unaged PDCPD is found to be about $10-13$ mol. $\mathrm{l}^{-1}$. It must be acknowledged that the relative concentration of acyclic and cyclic double bonds does not match well with the expected values (their concentration should theoretically be the same) but this has a very limited consequence on the following of our work since we only will model the overall double bond decay. At room temperature, PDCPD is in the glassy state and the low extent of molecular mobility results in an inefficient motional averaging of the ${ }^{1} \mathrm{H}-{ }^{1} \mathrm{H}$ dipolar couplings and thus, in a significant broadening of the ${ }^{1} \mathrm{H}$ NMR peaks. Such a situation renders the contribution from chemically-distinct protons difficult to resolve on the ${ }^{1} \mathrm{H}$ NMR spectrum of bulk PDCPD. For this reason, ${ }^{1} \mathrm{H}$ solid-state NMR experiments on PDCPD were performed at high magnetic field $\left({ }^{1} \mathrm{H}\right.$ Larmor frequency $\nu_{0}$ of $700 \mathrm{MHz}$ ) in order to improve the 

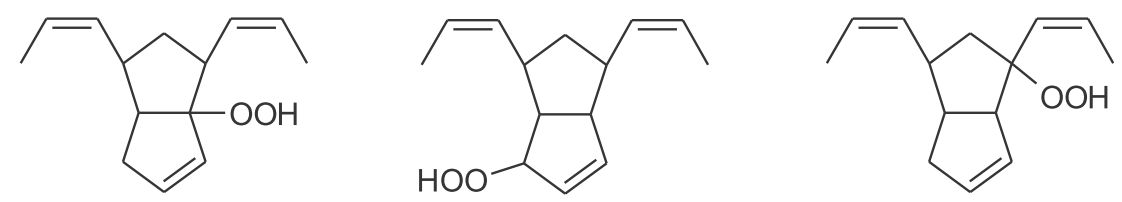

Fig. 4. Possible structures of hydroperoxides formed within a thermally-oxidized PDCDP.

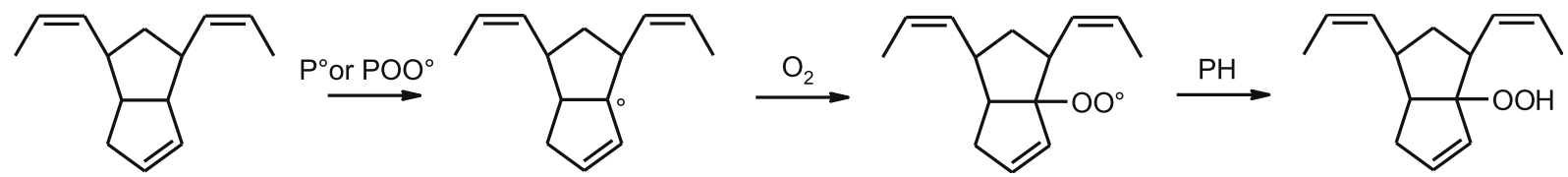

Scheme 1. Propagation step: hydrogen abstraction.

separation between the contributions from the different kinds of protons involved in unaged PDCPD. In addition, the ${ }^{1} \mathrm{H}$ one-pulse experiments were performed under sample rotation at an ultrafast spinning frequency $\left(v_{\mathrm{r}}=50 \mathrm{kHz}\right)$. The combination of both experimental conditions led to a clear separation of the peaks related to $-\mathrm{CH}=$ and saturated $\mathrm{CH} / \mathrm{CH}_{2}$ protons (Fig. 6) and thus enables a rather accurate quantification of the amount of double bonds. The peak at $5.6 \mathrm{ppm}$ is assigned to the $-\mathrm{CH}=$ protons whereas the one at $2.7 \mathrm{ppm}$ corresponds to the superimposition of the contributions from the saturated $\mathrm{CH}$ and $\mathrm{CH}_{2}$ protons. The deconvolution of the ${ }^{1} \mathrm{H}$ NMR spectrum of unaged PDCPD recorded under quantitative conditions was performed using two components with a Voigt line shape. The ratio between the areas of these components was found to be 1.99 , i.e. very close to the value expected by considering the chemical structure of PDCPD. From these solid-state NMR results, the double bond concentration for unaged PDCPD was estimated to be $13 \mathrm{~mol} \mathrm{l}^{-1}$, which is in good agreement with the value deduced from FTIR experiments and also consistent with the theoretical value $2 \times \rho / \mathrm{M}_{\mathrm{m}}$ ( $\rho$ is the density $=1045 \mathrm{~g} \mathrm{l}^{-1}$ and $\mathrm{M}_{\mathrm{m}}$ the molar mass of the monomer). This latter is expected to be about $15 \mathrm{moll}^{-1}$ having in mind that part of double bonds can disappear during the curing process and given the uncertainties on molar absortivities. It is possible that the strong heat release during PDCPD polymerization induces a very high crosslinking level (consistently with the higher density value than in Ref. [23]) and the disappearance of hexahydropentalene groups. This would explain why the $\beta$ relaxation process (associated to hexahydropentalene groups [24]) is absent in our case and why the double bond concentration is lower than $15 \mathrm{moll}^{-1}$.

\section{(2) In oxidized PDCPD}

The comparison of the IR spectra obtained on virgin PDCPD and PDCPD thermo-oxidized at $50^{\circ} \mathrm{C}$, under air (Fig. 2a and b) shows a decrease of the concentration of all types of double bonds, which indicates reactions between double bonds and radicals (Scheme 2).

Addition reactions of alkyl radicals (Scheme $2 \mathrm{a}$ ) could be a possible way of PDCPD crosslinking. This situation differs from the addition of peroxyl radicals (Scheme $2 \mathrm{2b}$ ) which does not lead to crosslinking, due to the formation of epoxide products. The occurrence of the reactions depicted in Scheme $2 \mathrm{~b}$ during the thermooxidation of PDCPD at $50^{\circ} \mathrm{C}$ is evidenced, from an experimental point of view, by the FTIR measurements which indicate the formation of epoxides (Fig. 2d).

Fig. 7a shows the changes of the concentration of each kind of double bond as a function of the exposure time at $50^{\circ} \mathrm{C}$. The corresponding consumption rates, determined as the maximal slope in Fig. 7b, are compared in Table 2. Conformational effects could explain a difference in reactivity with each kind of double bond. In a first approach, we considered the values for each kind of double bond to be almost the same, so that we will assume in the following that the reactivity of each of them is ruled by the same set of rate constants (NB: this hypothesis also allows to avoid mistakes due to uncertainties on the molar absorptivities).

The same experiments in air were performed at other ageing temperatures $\left(20^{\circ} \mathrm{C}, 30^{\circ} \mathrm{C}\right.$ and $\left.70^{\circ} \mathrm{C}\right)$ decreases in double bonds for the aged PDCPD are reported in Fig. 8a. The results obtained at a given temperature $\left(30^{\circ} \mathrm{C}\right)$, under different oxygen pressures, are shown in Fig. 8b while Fig. 8c depicts the variation of the double bond concentration with the exposure time, when the ageing is performed under $1 \mathrm{MPa}$ oxygen pressure, at different temperatures. All these data indicate that the double bond consumption rate increases with temperature and oxygen pressure. Besides, the double bond consumption rates are almost the same for ageing under $0.2 \mathrm{MPa}$ and $1 \mathrm{MPa}$. This feature leads us to consider oxidation under $1 \mathrm{MPa}$ as "representative" of the "oxygen excess conditions" in which $\mathrm{P}^{\circ}$ is almost instantaneously converted into $\mathrm{POO}^{\circ}$ so that analytical assessment of some rate constants is justified (see "Discussion").

Fig. 9 shows ${ }^{1} \mathrm{H}$ NMR spectrum of PDCPD after various aging time values $\left(4 \mathrm{~h}, 7 \mathrm{~h}\right.$ and $25 \mathrm{~h}$ ) at $50{ }^{\circ} \mathrm{C}$ under air. After $4 \mathrm{~h}$, the ${ }^{1} \mathrm{H}$ NMR spectrum remains qualitatively similar to the one of the unaged PDCPD (Fig. 9). The main difference stands in the presence of a peak of weak amplitude at $2.1 \mathrm{ppm}$. This contribution, which becomes again more significant after $7 \mathrm{~h}$ at $50^{\circ} \mathrm{C}$, may be assigned to protons from $\mathrm{CH}, \mathrm{CH}_{2}$ or $\mathrm{CH}_{3}$ covalently linked to $\mathrm{C}=\mathrm{O}$ groups. This result is in agreement with the reactions proposed in Schemes 3 and 4, as well as with the carbonyl build-up derived from FTIR measurements (Figs. 10 and 11): as the $\mathrm{CH}_{\mathrm{n}}-\mathrm{C}=\mathrm{O}$ protons detected by solid-state NMR, the fraction of carbonyl groups is rather low, but detectable, after $4 \mathrm{~h}$ at $50^{\circ} \mathrm{C}$, that is to say just above the induction period, while after $7 \mathrm{~h}$, the concentration of these species $\left(\mathrm{CH}_{\mathrm{n}}-\mathrm{C}=\mathrm{O}(\mathrm{NMR})\right.$ and $\mathrm{C}=\mathrm{O}$ (FTIR)) becomes significant. Interestingly, after $7 \mathrm{~h}$, another change induced by thermal oxidation may be observed on the ${ }^{1} \mathrm{H}$ NMR spectrum. An additional contribution between the two peaks of unaged PDCPD (2.7 ppm and $5.6 \mathrm{ppm}$ ) can also be observed after $7 \mathrm{~h}$, as a shoulder around $4.0 \mathrm{ppm}$, in the high-frequency side of the peak at $2.7 \mathrm{ppm}$. After an exposure for $25 \mathrm{~h}$ at $50^{\circ} \mathrm{C}$, the amplitude of this contribution gets higher and is now detected as a well-resolved peak at $4.5 \mathrm{ppm}$, corresponding to the proton(s) from $\mathrm{O}-\mathrm{CH}$ or $\mathrm{O}-\mathrm{CH}_{2}$ groups. At this stage, it is worth noting that this peak does not result from the protons of the epoxy rings formed during the thermo-oxidation at $50^{\circ} \mathrm{C}$ (Fig. $2 \mathrm{~d}$ ). These latter should indeed give rise to peaks overlapping the broad line at $2.7 \mathrm{ppm}$.

Let us now consider the variation of the double bond 


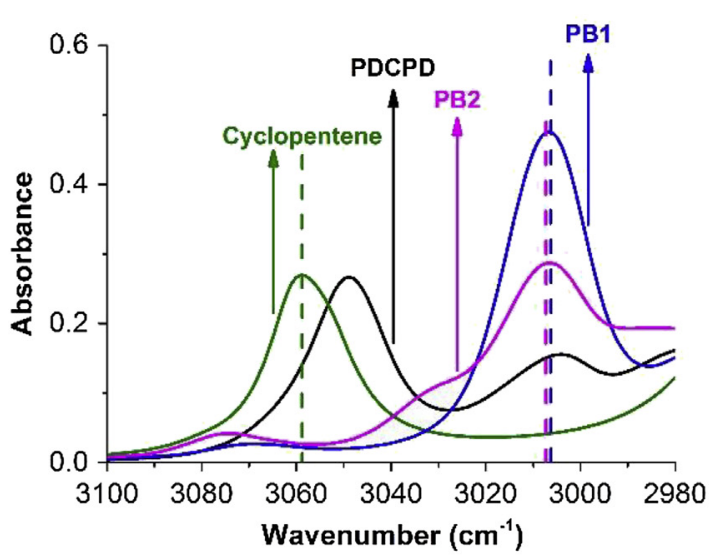

(a)

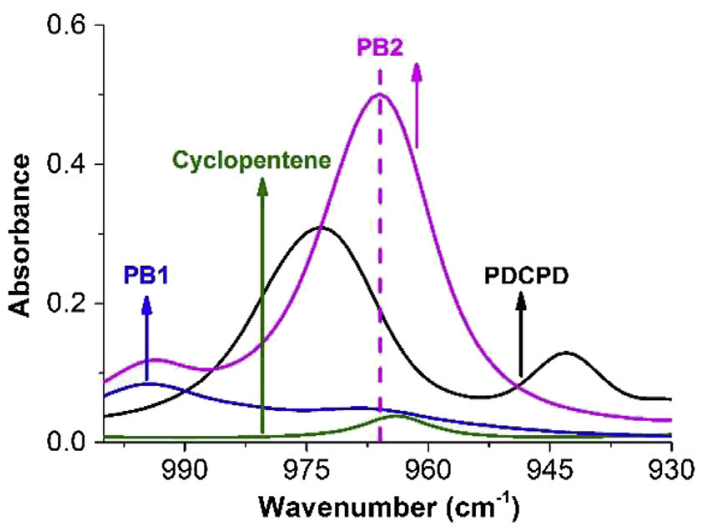

(b)

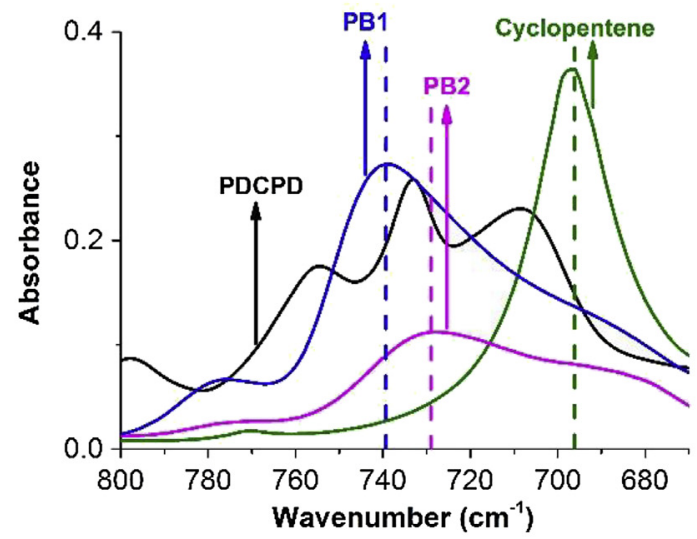

(c)

Fig. 5. Comparison of the FTIR spectra of purified, unaged PDCPD (in black) and model systems: cyclopentene (in green), cis-1,4-polybutadiene (in blue) and polybutadiene ( $36 \%$ of cis- 1,4 units, $55 \%$ of trans- 1,4 units and $9 \%$ of vinyl-1,2 units) (in magenta). (For interpretation of the references to colour in this figure legend, the reader is referred to the Web version of this article.)

concentration with the aging time at $50{ }^{\circ} \mathrm{C}$. As can be seen in Fig. 9, the relative amplitude of the peak at $5.6 \mathrm{ppm}$ with respect to the one at $2.7 \mathrm{ppm}$ decreases during aging while it also displays a significant broadening. Due to the chemical modification of the PDCPD matrix, a distribution of the local region surrounding the $=\mathrm{CH}$ - protons, inducing a distribution of the ${ }^{1} \mathrm{H}$ chemical shift

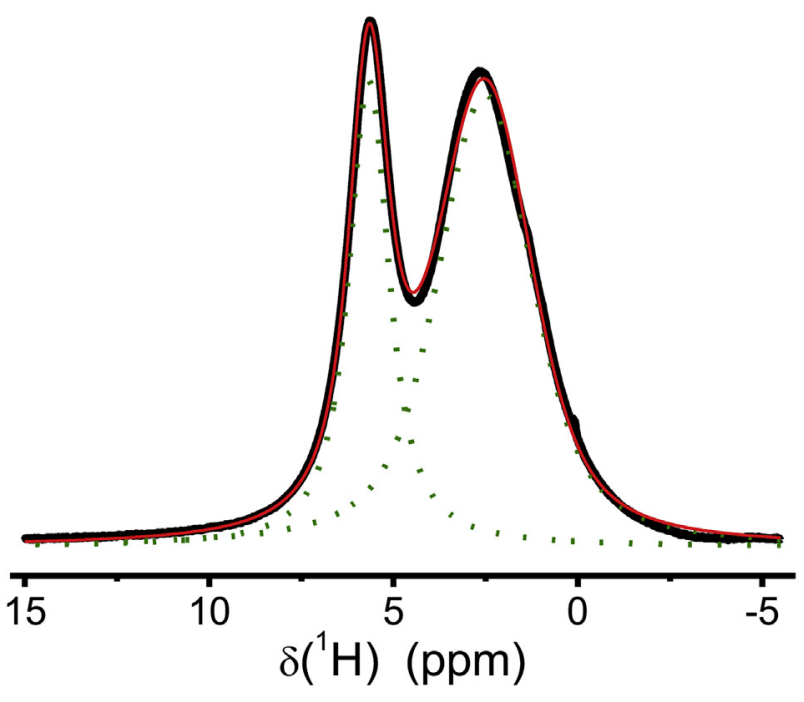

Fig. 6. One-pulse ${ }^{1} \mathrm{H}$ MAS NMR spectrum of purified, unaged PDCDP, recorded at a ${ }^{1} \mathrm{H}$ Larmor frequency $\nu_{0}$ of $700 \mathrm{MHz}$ and a MAS frequency $v_{\mathrm{r}}$ of $50 \mathrm{kHz}$. The deconvolution of the spectrum (red solid line) using Voigt line shapes (green dotted lines) is also included. (For interpretation of the references to colour in this figure legend, the reader is referred to the Web version of this article.)

value, occurs. The area under the peak at $5.6 \mathrm{ppm}$ should thus be considered, in order to investigate the decrease in double bond concentration with the exposure time at $50{ }^{\circ} \mathrm{C}$. The deconvolution performed in the case of the unaged PDCPD was not used because above $7 \mathrm{~h}$ of thermal aging, at least four contributions, with a significant overlap for some of them, are involved in the ${ }^{1} \mathrm{H}$ NMR spectrum. The interplay between the different fitting parameters would then lead to a significant inaccuracy on the fraction $f$ of protons involved in double bonds within aged PDCPD. To circumvent this difficulty, f was determined using half of the peak area $A$ $\mathrm{CH}=$, integrating from the high frequency side down to the peak maximum frequency. f may indeed be estimated by calculating $2 \times A_{-\mathrm{CH}}=\mid A_{\text {total }}, A_{\text {total }}$ denoting the total area under the ${ }^{1} \mathrm{H}$ NMR spectrum.

It is interesting to note that the NMR and FTIR methods give almost the same trend for samples aged for 0,4 and $7 \mathrm{~h}$. At very high oxidation levels (i.e. $25 \mathrm{~h}$ and more), which is not the aim of this paper, a discrepancy can be observed between NMR and FTIR. Even if it is not the subject of this study it could be possible that conjugated structures are formed and display shifted absorptions for vinyl C-H. In other words, NMR detects the total amount of residual double bonds whereas FTIR detects the unreacted ones (which is the "fuel" of the oxidation process). We however acknowledge that this argument cannot be verified in the present paper so that the mechanism of degradation at high conversion degree remains an open issue. Our approach, which considers mainly low degradation levels, is supported by the fact that mechanical behavior of PDCPD is largely affected by low levels of oxidation (Fig. 12).

Lastly, one should also note that a peak at $9.7 \mathrm{ppm}$ characterized by a weak, but increasing amplitude is observed on the ${ }^{1} \mathrm{H}$ NMR spectra of the aged PDCPD (see Appendix 1). These protons may be related to carboxylic acid protons or aldehydic protons, this latter assignment being in agreement with the reactions proposed in Scheme 3.

\subsection{Formation of carbonyls}

The FTIR measurements reported in Fig. 2c also show the 


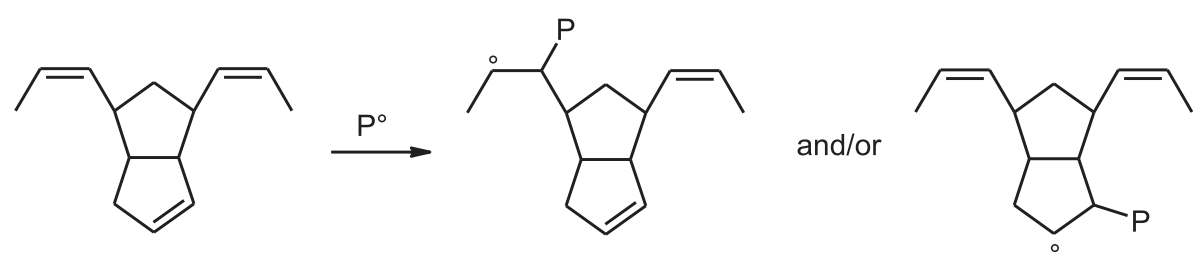

(a)

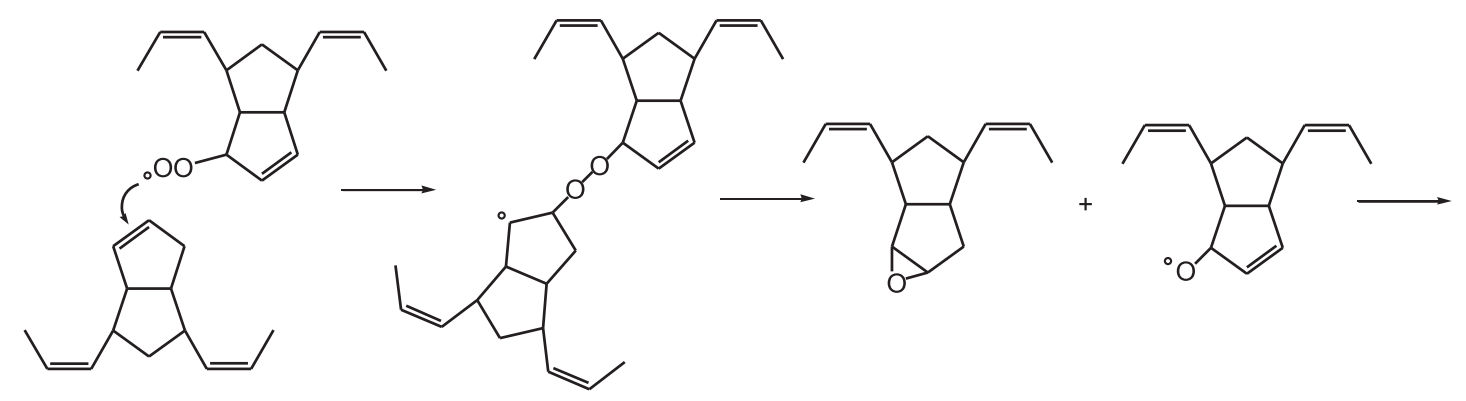

(b)

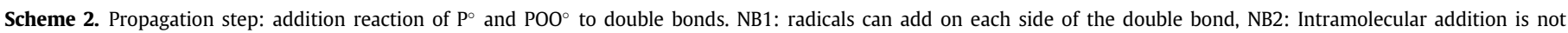
considered in the case of PDCPD due to its structural hindrance.

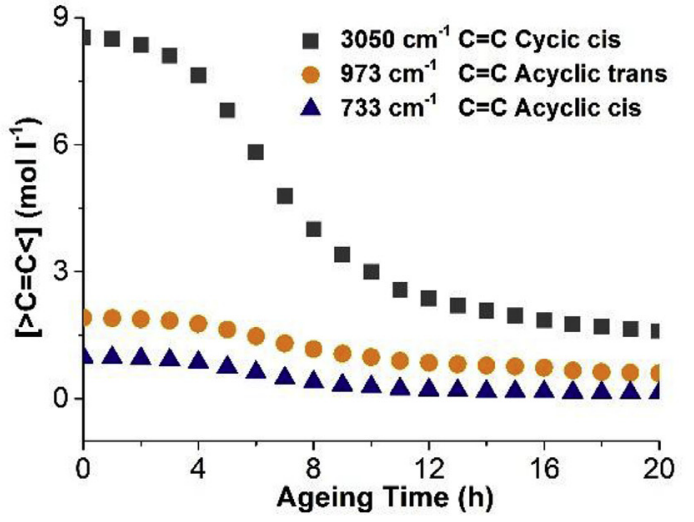

(a)

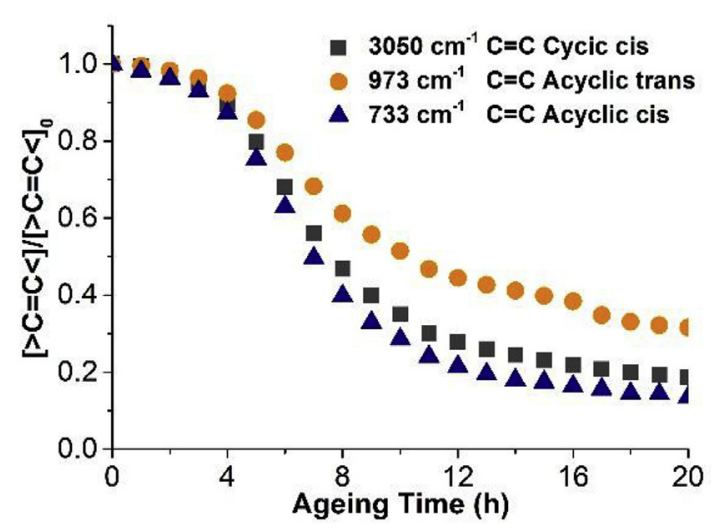

(b)

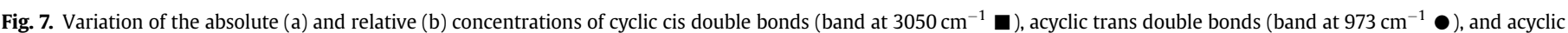

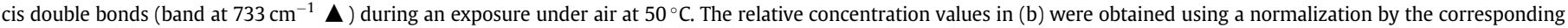
concentrations of the unaged PDCPD.

formation of a band at ca $1710 \mathrm{~cm}^{-1}$ corresponding to carbonyl functions. As can be seen in Fig. 10a, the shapes of the carbonyl band are similar under different oxidation conditions (temperature, oxygen pressure) which means that the corresponding oxidation

Table 2

Initial concentration consumption rate $\left(\mathrm{v}_{\mathrm{F}}\right)$ and relative consumption rate (relative $\mathrm{r}_{\mathrm{F}}=\mathrm{r}_{\mathrm{F}} /[\mathrm{C}=\mathrm{C}]_{0}$ ) of the different kinds of double bonds in PDCPD.

\begin{tabular}{llll}
\hline & {$[\mathrm{C}=\mathrm{C}]_{0}\left(\mathrm{~mol} \mathrm{l}^{-1}\right)$} & $\mathrm{r}_{\mathrm{F}}\left(\mathrm{mol} \mathrm{l}^{-1} \mathrm{~s}^{-1}\right)$ & Relative $\mathrm{r}_{\mathrm{F}}\left(\mathrm{s}^{-1}\right)$ \\
\hline Acyclic trans: $973 \mathrm{~cm}^{-1}$ & 1.91 & $4.24 \mathrm{E}-5$ & $2.22 \mathrm{E}-5$ \\
Acyclic cis: $733 \mathrm{~cm}^{-1}$ & 0.99 & $3.43 \mathrm{E}-5$ & $3.47 \mathrm{E}-5$ \\
Cyclic cis: $3050 \mathrm{~cm}^{-1}$ & 8.53 & $2.44 \mathrm{E}-4$ & $2.86 \mathrm{E}-5$ \\
\hline
\end{tabular}

products of PDCPD involve the same kind of carbonyl groups. They can originate from alkoxy radicals formed during:

(1) the initiation step during which unimolecular and bimolecular hydroperoxide decomposition can occur (Scheme 3):

$$
\begin{aligned}
& \mathrm{POOH} \rightarrow \mathrm{PO}^{\circ}+{ }^{\circ} \mathrm{OH} \\
& \mathrm{POOH}+\mathrm{POOH} \rightarrow \mathrm{POO}^{\circ}+\mathrm{PO}^{\circ}+\mathrm{H}_{2} \mathrm{O}
\end{aligned}
$$

(2) the termination step by disproportionation by a Russell mechanism $[25,26]$ (Scheme 4),

(3) the decomposition of $\mathrm{POOP}^{\circ}$ (Scheme 2) that rearrange into $\mathrm{PO}^{\circ}$. 


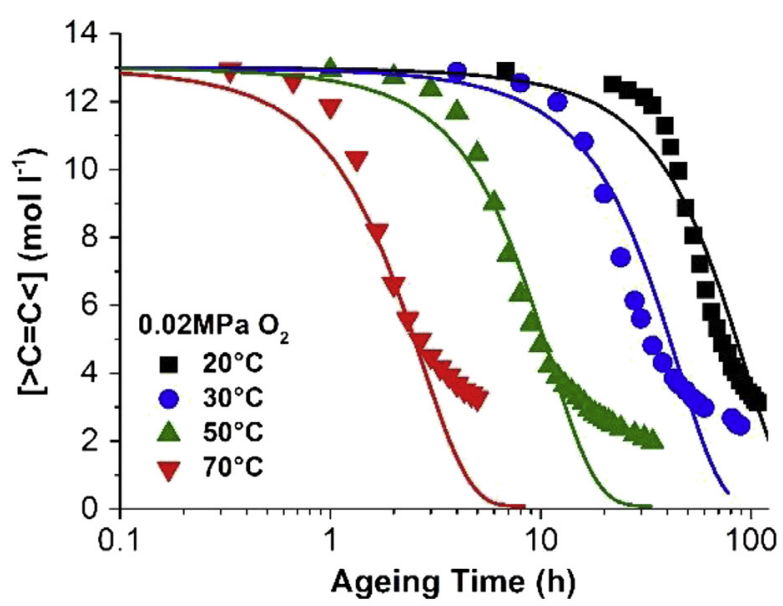

(a)

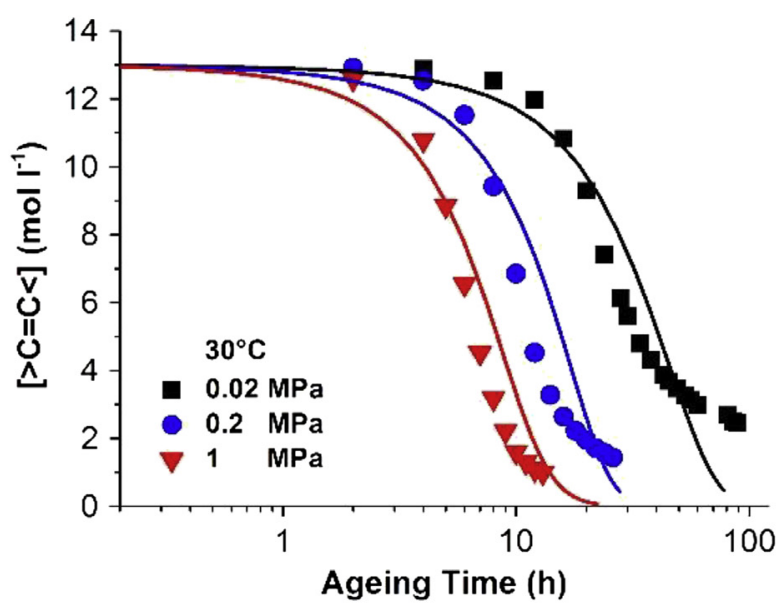

(b)

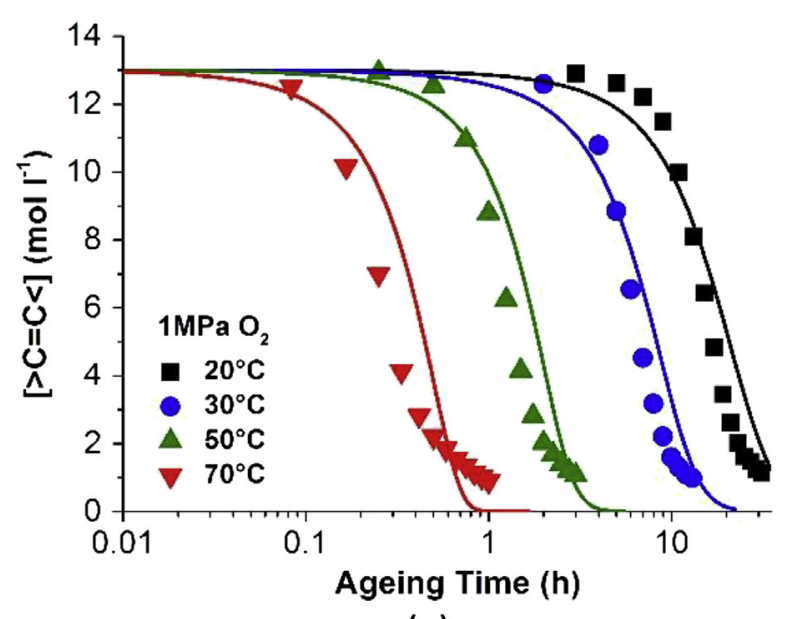

(c)

Fig. 8. Double bond consumption under various ageing conditions: in air at different temperatures (a) Double bonds consumption at $30^{\circ} \mathrm{C}$ under different oxygen pressures (b); Double bonds consumption under $1 \mathrm{MPa}$ oxygen pressure at different temperatures (c). The solid lines correspond to the predictions by the kinetic model.

The concentration in carbonyl increases with ageing time accompanied a period of induction (Fig. 10b). Meanwhile, the

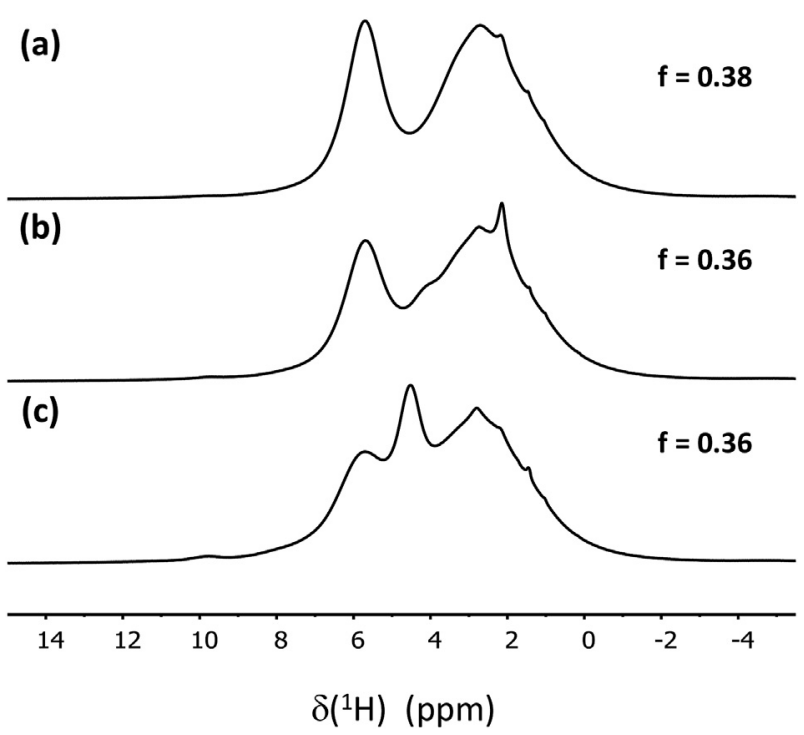

Fig. 9. Changes of the one-pulse ${ }^{1} \mathrm{H}$ MAS NMR spectrum of PDCDP thermo-oxidized at $50{ }^{\circ} \mathrm{C}$ under air, as a function of the exposure time: (a) $4 \mathrm{~h}$, (b) $7 \mathrm{~h}$ and (c) $25 \mathrm{~h}$. The experiments were carried out at a ${ }^{1} \mathrm{H}$ Larmor frequency $\nu_{0}$ of $700 \mathrm{MHz}$ and a MAS frequency $v_{\mathrm{r}}$ of $50 \mathrm{kHz}$. The fraction $\mathrm{f}$ of protons from the double bonds within aged PDCPD is also included and should be compared to $f=0.43$, obtained for unaged PDCPD.

double bond concentration decreases as a function of ageing time with a period of induction. The kinetics of carbonyl build-up under several conditions are shown in Fig. 11a-c.

For all conditions considered here, carbonyl formation over ageing time follows the same behavior. First an induction period is observed where carbonyl concentration remains very low, and then a classic self-acceleration form occurs. It appears, as expected, that an increase in temperature leads to a decrease of the induction period and an increase in oxidation rate. The oxidation process can also be accelerated by increasing oxygen pressure between $0.02 \mathrm{MPa}$ and $0.5 \mathrm{MPa}$ (Fig. 11b). Above 0.5 MPa, the oxidation process is not affected by oxygen pressure anymore showing that $0.5 \mathrm{MPa}$ can be considered as the critical pressure. This behavior is observed for all ageing temperatures (Fig. 11c).

The carbonyl build-up obtained under $1 \mathrm{MPa}$ oxygen pressure at different temperatures ranging between $20^{\circ} \mathrm{C}$ and $70^{\circ} \mathrm{C}$ (Fig. 11c) also display the self-accelerated shape mentioned above.

\subsection{Formation of epoxides}

FTIR spectra of thermo-oxidized PDCPD (Fig. 2d) display two bands at ca $852 \mathrm{~cm}^{-1}$ and $837 \mathrm{~cm}^{-1}$ that correspond to the symmetric ring deformation of epoxides. Such oxidation products are also involved in the thermo-oxidative behavior of polybutadiene [7]. The intensity of these absorption bands continuously increases during aging in air at $50{ }^{\circ} \mathrm{C}$, but remains very weak. Consistently with NMR data (Fig. 9), those species will be neglected in the following.

\subsection{Mechanical properties}

Tensile behavior of $60 \mu \mathrm{m}$ thick films aged at $80^{\circ} \mathrm{C}$ are represented in Fig. 12 for several concentrations of carbonyls and double bonds. It clearly appears that oxidation leads to a decrease in strain at break as well as an increase in stress at yield. Moreover the decrease in maximal strain can be related to concentration of remaining double bonds and formed carbonyls. This means that 


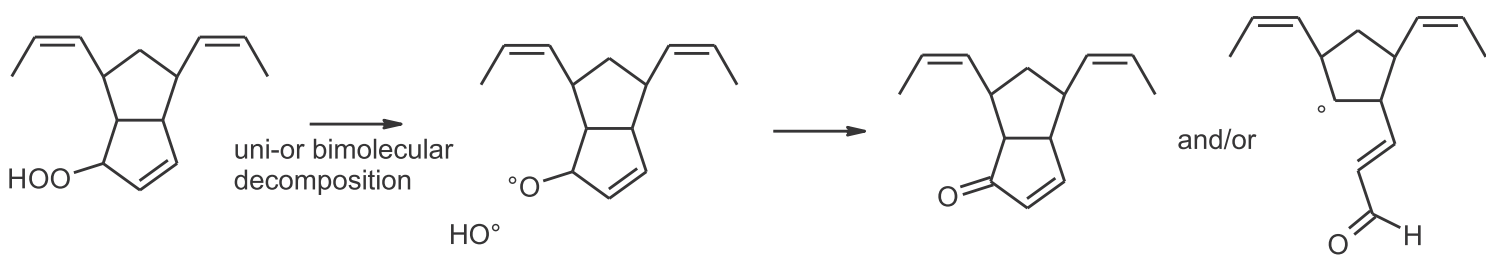

(a)<smiles>C/C=C\C1CC(O)(/C=C\C)C2C=CCC12</smiles>

uni-or bimolecular decomposition
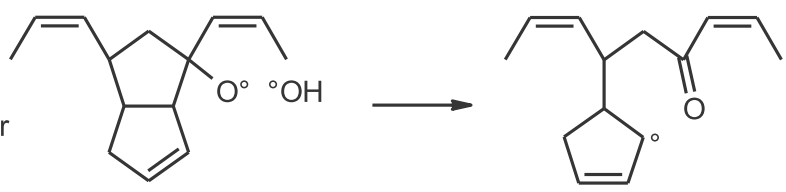

(b)

Scheme 3. Initiation step: hydroperoxide decomposition.
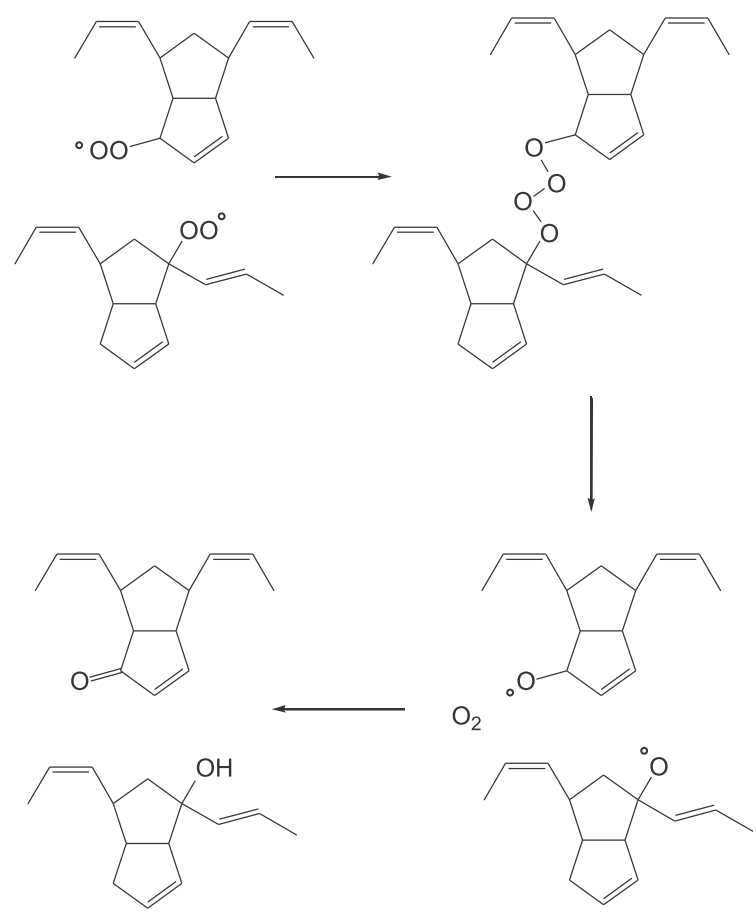

Scheme 4. Termination step: Russell disproportionation of $\mathrm{PO}^{\circ}$.

using a model able to predict chemical changes during oxidation would allow the mechanical behavior of the polymer considered here to be evaluated.

\section{Discussion}

The aim of this section is to derive a kinetic model based on the proposed chemical reactions and the reported chemical changes under several ageing conditions in relation to the changes in mechanical properties.

\subsection{Proposal for a kinetic model}

According to the experimental data describing chemical changes of thermo-oxidized PDCPD reported above, the following mechanistic scheme may be used for modeling the kinetic curves obtained during the ageing of PDCPD:

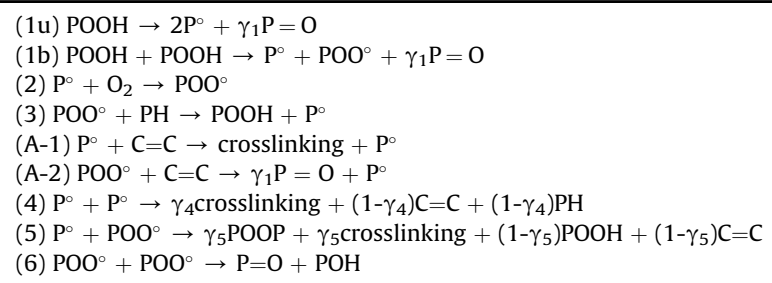

For summarize, it can be considered as an adaptation of the mechanistic scheme proposed by Tobolski et al. [27] for the autoxidation of hydrocarbons (reactions $1 \mathrm{u}, 1 \mathrm{~b}, 2,3$ and 6), together with some specific reactions for the reactivity of double bonds (reactions (a1) and (a2) [7,12,28]) and the effect of oxygen pressure (or concentration (reactions (4) and (5) [7]).

$\gamma_{1}, \gamma_{4}$ and $\gamma_{5}$ are the yields respectively for carbonyls from $\mathrm{PO}^{\circ}$ decomposition, crosslinking from $\mathrm{P}^{\circ}+\mathrm{P}^{\circ}$ and $\mathrm{P}^{\circ}+\mathrm{POO}^{\circ}$ coupling.

$\gamma_{1}$ was estimated close to 0.25 [29]. $\gamma_{4}$ was fixed equal to 0 , and it was checked that the numerical model was found to be insensitive to the value of $\gamma_{5}$ fixed equal to 0 since no POOP were detected in DSC.

$\left[\mathrm{O}_{2}\right]$ can be calculated by the following equation: $\left[\mathrm{O}_{2}\right]=\mathrm{S}_{\mathrm{O} 2} \times \mathrm{P}_{\mathrm{O} 2}$, $\mathrm{S}_{\mathrm{O} 2}$ is the solubility coefficient of oxygen in PDCPD: $\mathrm{S}_{\mathrm{O} 2}=10^{-7} \mathrm{~mol} \mathrm{l}^{-1} \mathrm{~Pa}^{-1}[13]$

In this work, the PDCPD films are thin enough $(5-7 \mu \mathrm{m})$ to neglect the gradient of oxygen concentration through the thickness. The initiation step is composed of uni- and bi-molecular decompositions of $\mathrm{POOH}$. It is here considered that both reactions may proceed simultaneously even if under high oxygen pressures, 


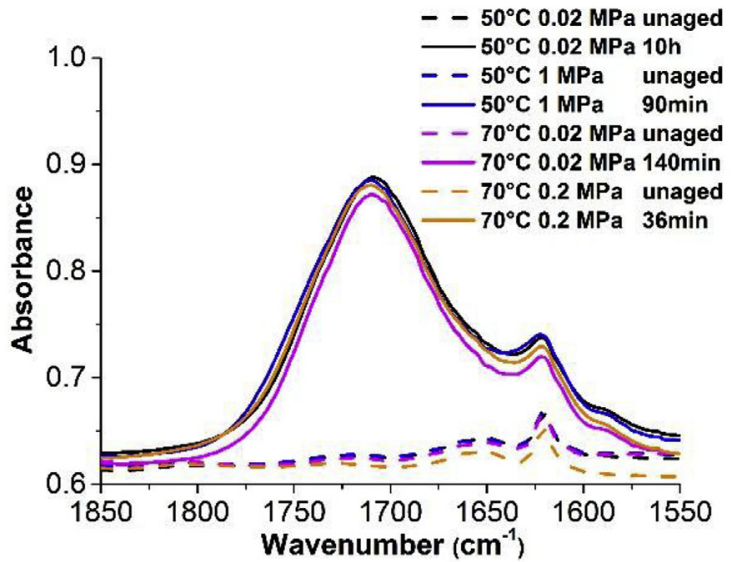

(a)

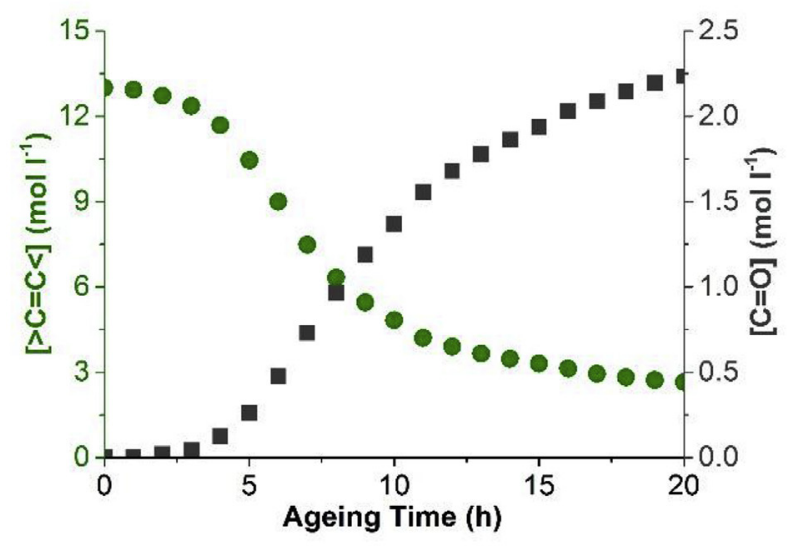

(b)

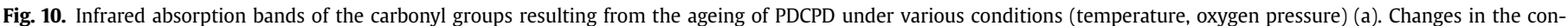
centration of carbonyls ( $)$ and double bonds ( ) during ageing at $50^{\circ} \mathrm{C}$ under air (b).

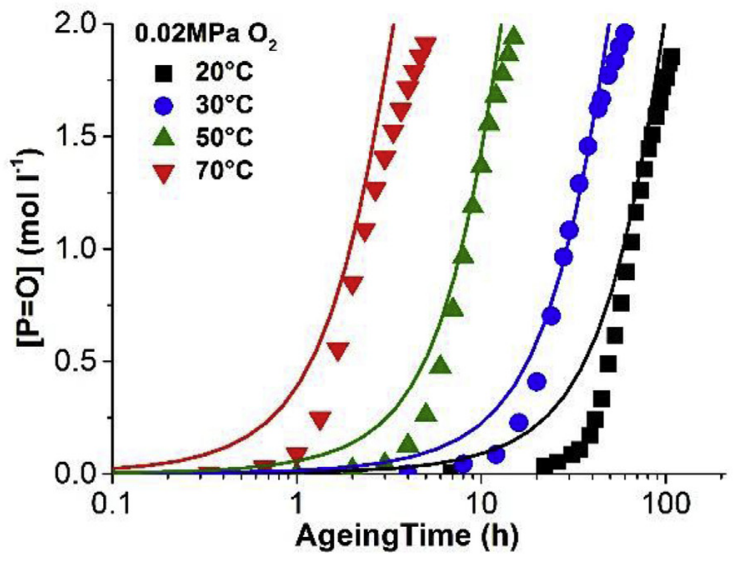

(a)

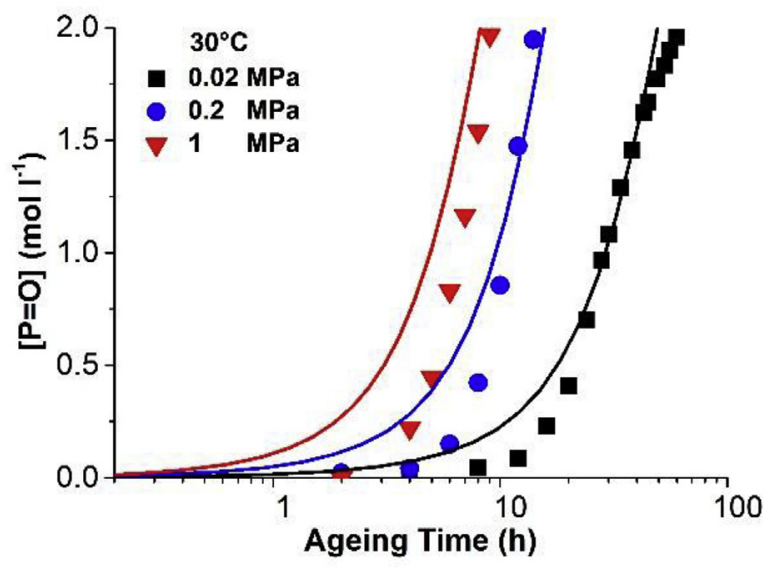

(b)

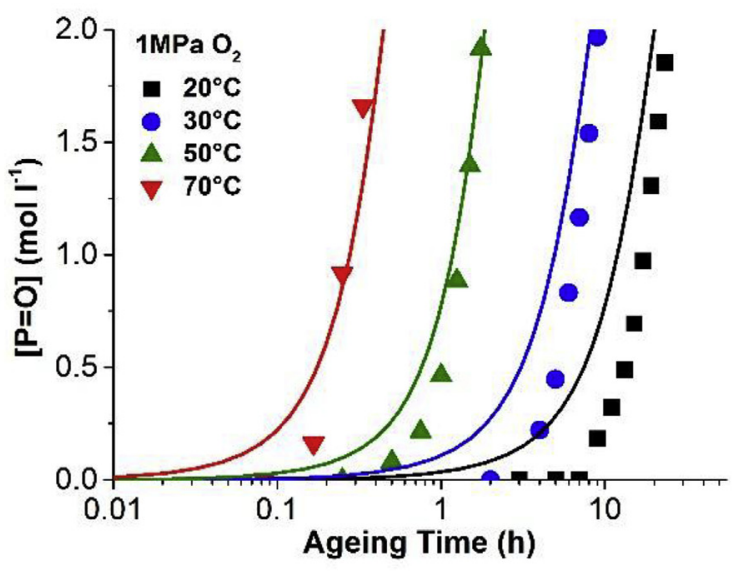

(c)

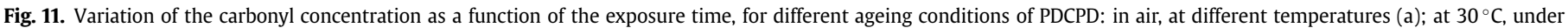
different oxygen pressures (b) under 1 MPa oxygen pressure, at different temperatures (c). 


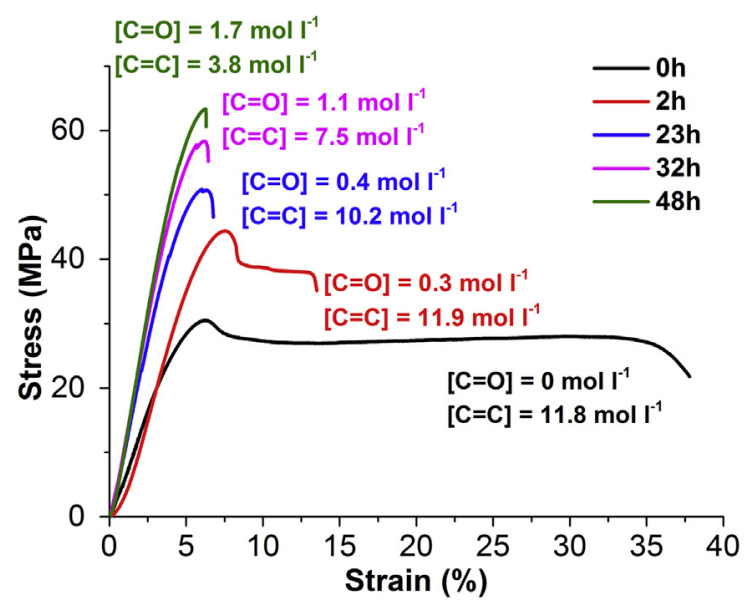

Fig. 12. Tensile curves for PDPCD samples with varying exposure times at $80^{\circ} \mathrm{C}$ under air. NB: Concentrations were obtained by using a correction corresponding to $\left(\frac{A_{\mathrm{CH} 2}}{e}\right)$ differences in samples tested for tensile tests and ageing tests monitored by FTIR.

the oxidation is predominately bimolecular [7]. Under low oxygen pressures, the concentration of hydroperoxides is low. This feature is presently under investigation [29].

The resulting system of differential equations can be derived from the kinetic scheme (Appendix 2). It can be resolved with the following boundary values at $\mathrm{t}=0$ :

$[\mathrm{C}=\mathrm{C}]=[\mathrm{C}=\mathrm{C}]_{0}=13 \mathrm{~mol}^{-1}$ (adjusted from FTIR measurements).

$[\mathrm{PH}]=[\mathrm{PH}]_{0}=2[\mathrm{C}=\mathrm{C}]_{0}$ (since each double bond is surrounded by two allylic $\mathrm{C}-\mathrm{H}$ likely to react in the oxidation process)

$\left[\mathrm{P}^{\circ}\right]_{0}=\left[\mathrm{POO}^{\circ}\right]_{0}=0$

$[\mathrm{POOH}]=[\mathrm{POOH}]_{0}=10^{-2} \mathrm{~mol} \mathrm{l}^{-1}$

In order to solve the inverse problem, an analytical approach will be used, assuming some simplifications:

- The initiation step is considered as being predominantly bimolecular in the steady state where $\mathrm{POOH}$ is maximal.

- The maximum carbonyl growth rate is considered to be close to the theoretical steady-state rate, which may be calculated by assuming the substrate consumption to be negligible. Therefore, under this assumption, the steady state is considered to be reached at low conversion.

\subsection{Analytical solution and estimation of the termination and} propagation rate constants

The steady-state regime implies that:

$\frac{d\left[P^{\circ}\right]}{d t}+\frac{d\left[P O O^{\circ}\right]}{d t}=0$

$\frac{d[\mathrm{POOH}]}{d t}=0$

Combined with equations given in Appendix 1, it gives:

$2 k_{1 b}[\mathrm{POOH}]^{2}=2 k_{4}\left[\mathrm{P}^{\circ}\right]^{2}+2 k_{5}\left[\mathrm{P}^{\circ}\right]\left[\mathrm{POO}^{\circ}\right]+2 k_{6}\left[\mathrm{POO}^{\circ}\right]^{2}$
$2 k_{1 b}[\mathrm{POOH}]^{2}=k_{3}\left[\mathrm{POO}^{\circ}\right][\mathrm{PH}]+k_{5}\left(1-\gamma_{5}\right)\left[\mathrm{P}^{\circ}\right]\left[\mathrm{POO}^{\circ}\right]$

In the oxygen-excess regime, the termination reactions (4), (5) and the addition reactions (A-1) can be suppressed, and the following expressions for the concentration of reactive species may be derived:

$$
\begin{aligned}
& {\left[\mathrm{POO}^{\circ}\right]_{\infty}=\frac{k_{3}[\mathrm{PH}]}{2 k_{6}}} \\
& {[\mathrm{POOH}]_{\infty}=\frac{k_{3}[\mathrm{PH}]}{2 \sqrt{k_{1 b} \cdot k_{6}}}}
\end{aligned}
$$

Therefore, the rate of carbonyl production under oxygen excess can be described by the following equation:

$$
\begin{aligned}
r_{\text {ox }, s}=\frac{d[P=O]}{d t} & =\gamma_{1} k_{1 b}[\mathrm{POOH}]^{2}+k_{6}\left[\mathrm{POO}^{\circ}\right]^{2}+\gamma_{1} k_{a 2}\left[\mathrm{POO}^{\circ}\right][F] \\
& =\frac{\left(\gamma_{1}+1\right) k_{3}^{2}[\mathrm{PH}]^{2}}{4 k_{6}}+\frac{\gamma_{1} k_{a 2} k_{3}[\mathrm{C}=C]^{2}}{k_{6}} \\
& =\frac{\left(\gamma_{1}+1\right) k_{3}^{2}[\mathrm{PH}]^{2}}{4 k_{6}}+\frac{\gamma_{1} k_{a 2} k_{3}[\mathrm{PH}]^{2}}{4 k_{6}}
\end{aligned}
$$

Similarly, in the oxygen-excess regime, the consumption rate of double bonds is expressed as:

$$
\begin{aligned}
r_{C=C, S}=-\frac{d[C=C]}{d t} & =k_{a 2}\left[\mathrm{POO}^{\circ}\right][C=C]=\frac{k_{a 2} k_{3}[\mathrm{PH}][C=C]}{2 k_{6}} \\
& =\frac{k_{a 2} k_{3}[C=C]^{2}}{k_{6}}
\end{aligned}
$$

Our strategy is the following:

- $\mathrm{k}_{2}=10^{8} 1 \mathrm{~mol}^{-1} \mathrm{~s}^{-1}$ [28] and $\mathrm{k}_{3}$ [7] are chosen from literature values.

- $\mathrm{k}_{1 \mathrm{~b}}$ are obtained by means of the thermolysis of hydroperoxides [29].

As a result, $\mathrm{k}_{\mathrm{a} 2}$ and $\mathrm{k}_{6}$ may be calculated according to the following equation:

$k_{6}=\frac{\left(\gamma_{1}+1\right) k_{3}^{2}[P H]^{2}}{4\left(r_{o x, S}-\gamma_{1} r_{C=C, S}\right)}$

$k_{a 2}=\frac{k_{6} r_{C=C, s}}{k_{3}[C=C]^{2}}$

The values of $\mathrm{k}_{6}$ and $\mathrm{k}_{\mathrm{a} 2}$, deduced from this analytical calculation, are compared with values obtained for rubbery polymers (polyisoprene [28], polychloroprene [12]) and model molecules (cyclopentene [30], indene) as shown in Fig. 10. The fact that they are several orders of magnitude lower for PDCPD than for rubbery polymers and liquid compounds (Fig. 13) can be discussed in terms of mobility-controlled reactions. To summarize and complete previously given explanations $[8,3]$ :

- $\mathrm{POO}^{\circ}$ reactivity is lowered because of control by segmental relaxation,

- this impacts very strongly $\mathrm{POO}^{\circ}+\mathrm{POO}^{\circ}$ termination reactions.

Data from Fig. 10b suggests that this effect if lower for 


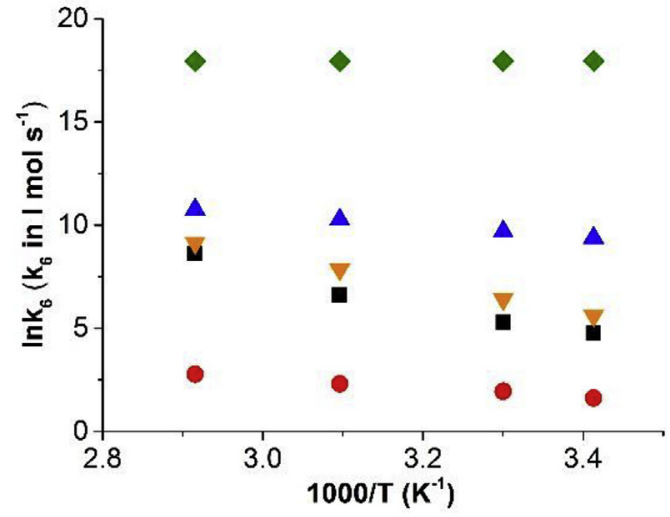

(a)

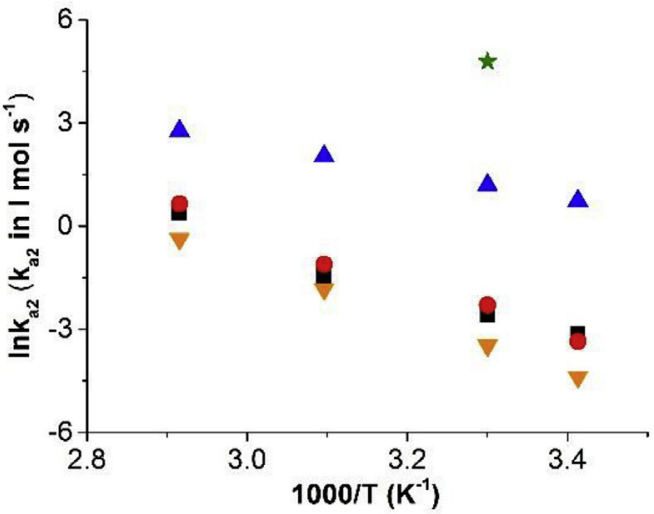

(b)

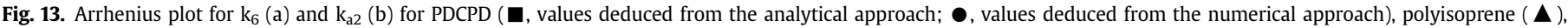
polychloroprene $(\boldsymbol{\nabla})$, cyclopentene $(\bullet)$ and indene $(\star)$ for exposure at $50^{\circ} \mathrm{C}$.

$\mathrm{POO}^{\circ}+\mathrm{C}=\mathrm{C}$ reaction consistently with the fact that in such reactions, $\mathrm{C}=\mathrm{C}$ are in high concentration and their reactivity is not limited by diffusion compared to $\mathrm{POO}^{\circ}+\mathrm{POO}^{\circ}$ where the reactivity of the two reactants is limited by diffusion.

\subsection{Numerical simulation}

Following the analytical resolution of the system of equations reported in Appendix 2, a numerical resolution has been carried out by the inverse method, without the assumptions used in Section 4.2.

In the oxygen-excess regime, only a few parameters play a role in the oxidation kinetics: $\mathrm{k}_{1 \mathrm{~b}}, \mathrm{k}_{2}, \mathrm{k}_{3}, \mathrm{k}_{6}$ and $\mathrm{k}_{\mathrm{a} 2}$. These are first estimated from the analytical approach (see previous paragraph).

Hence, $\mathrm{k}_{1 \mathrm{u}}, \mathrm{k}_{4}$ and $\mathrm{k}_{5}$ were estimated from the best fitting of carbonyl, double bonds and hydroperoxide concentrations in air. The value of $\mathrm{k}_{6}$ obtained analytically allows the experimental data related to the carbonyls to be modelled. However, the values of $\mathrm{k}_{6}$ and $\mathrm{k}_{\mathrm{a} 2}$ have been adjusted in order to account simultaneously for changes over ageing time for $\mathrm{POOH}, \mathrm{C}=\mathrm{O}$ and $\mathrm{C}=\mathrm{C}$. Figs. $8 \mathrm{c}$ and $11 \mathrm{c}$ display the simulation curves for the double bond consumption and the carbonyl build-up in the oxygen-excess regime.

After focusing on the case of PDCPD oxidation under high oxygen pressure, the situation of oxidation under low oxygen pressure is considered. For this purpose, another addition reaction rate constant $\left(\mathrm{k}_{\mathrm{a} 1}\right.$ corresponding to the reaction of $\mathrm{P}^{\circ}$ with $\left.\mathrm{C}=\mathrm{C}\right)$ and the other termination rate constants $\left(\mathrm{k}_{4}\right.$ for $\mathrm{P}^{\circ}+\mathrm{P}^{\circ}, \mathrm{k}_{5}$ for $\left.\mathrm{P}^{\circ}+\mathrm{POO}^{\circ}\right)$ should be determined.

Based on the results obtained under excess oxygen, the numerical simulations for PDCPD thermally-oxidized in air were more easily performed. All the values derived from the obtained by simulation in the oxygen-excess regime (i.e. $\mathrm{k}_{1 \mathrm{u}}, \mathrm{k}_{1 \mathrm{~b}}, \mathrm{k}_{2}, \mathrm{k}_{3}, \mathrm{k}_{6}, \mathrm{k}_{\mathrm{a} 2}$ and $\left.\gamma_{1 b}\right)$ were indeed fixed. Similary, $k_{4}$ and $k_{5}$ and $k_{a 1}$ can be obtained by solving the inverse problem. The numerical simulation curves describing the changes over time for carbonyls and double bonds during ageing in air are shown in Figs. 7a and 9a. The resulting kinetic parameters together with their activation energies are presented in Table 3. Most of the "rules" expected for kinetic parameters for radicals processes seem to be verified: $\mathrm{k}_{4}>\mathrm{k}_{5} \gg \mathrm{k}_{6}$ [31], $\mathrm{E}_{4} \sim \mathrm{E}_{5} \sim 0 \mathrm{~kJ} \mathrm{~mol}^{-1}[7,12,28], \mathrm{k}_{\mathrm{a} 1} \gg \mathrm{k}_{\mathrm{a} 2}$ [7,12,28]. The values of kinetic parameters remain to be investigated in full with the possible influence of catalyst by-produts $[13,29]$. However, at this stage we now have a kinetic model describing the oxidation of unstabilized PDCPD in cases where oxidation is not limited by oxygen diffusion.

\section{Conclusions}

The thermal oxidation of PDCPD was studied under several temperatures and oxygen pressures. Beyond an induction period, the ageing was shown to induce a very strong decrease of the double bond concentration together with a strong increase of the carbonyl concentration. These modifications at the chemical level are responsible for significant changes in some of the mechanical properties of thermo-oxidized PDCPD.

A kinetic model was developed on the basis of a reasonable mechanistic scheme so as to simulate and predict the chemical changes occurring in PDCPD during aging. One of the main issues associated with such kinetic models is the high number of kinetic parameters to be determined. To overcome this concern, ageing of PDCPD under oxygen excess was used to "isolate" some of the key values among the kinetic parameters. The resulting kinetic model can simulate both carbonyl build-up and double bond consumption. Since hydroperoxides are key species of the oxidation process being quantifiable without the use of adjustable parameters (such

Table 3

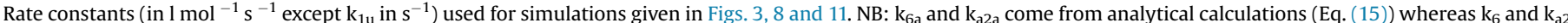
come from numerical solution (i.e. from curve fitting).

\begin{tabular}{|c|c|c|c|c|c|c|c|c|c|c|c|}
\hline $\mathrm{T}\left({ }^{\circ} \mathrm{C}\right)$ & $\mathrm{k}_{1 \mathrm{u}} \times 10^{6}$ & $\mathrm{k}_{1 \mathrm{~b}} \times 10^{7}$ & $\begin{array}{l}\mathrm{k}_{2} \\
\times 10^{-8}\end{array}$ & $\begin{array}{l}\mathrm{k}_{3} \\
\times 10^{3}\end{array}$ & $\begin{array}{l}\mathrm{k}_{4} \\
\times 10^{-8}\end{array}$ & $\begin{array}{l}\mathrm{k}_{5} \\
\times 10^{-8}\end{array}$ & $\mathrm{k}_{6}$ & $\mathrm{k}_{6 \mathrm{a}}$ & $\begin{array}{l}\mathrm{k}_{\mathrm{a} 1} \\
\times 10^{-3}\end{array}$ & $\mathrm{k}_{\mathrm{a} 2}$ & $\mathrm{k}_{\mathrm{a} 2 \mathrm{a}}$ \\
\hline 20 & 1.5 & 1.7 & 1.0 & 3.6 & 5.0 & 1.0 & 5 & 117 & 6.0 & 0.035 & 0.04 \\
\hline 30 & 3 & 3.9 & 1.0 & 9.1 & 5.0 & 1.3 & 7 & 199 & 7.0 & 0.1 & 0.08 \\
\hline 50 & 12 & 18 & 1.0 & 48 & 5.0 & 1.7 & 10 & 758 & 9.0 & 0.37 & 0.24 \\
\hline 70 & 60 & 70 & 1.0 & 210 & 5.0 & 2.4 & 16 & 5468 & 1.1 & 2.2 & 1.47 \\
\hline $\mathrm{E}_{\mathrm{a}}$ & 61 & 62 & 1 & 68 & 1 & 14 & 16 & 64 & 10 & 72 & 58 \\
\hline $\mathrm{R}^{2}$ & 0.994 & 0.999 & 1 & 1 & 1 & 0.991 & 0.991 & 0.973 & 0.999 & 0.989 & 0.972 \\
\hline
\end{tabular}


as yields from a modeling point of view, or absorptivity values from an experimental point of view), the simulation of their formation and consumption was used for a better validation of the kinetic model.

The final kinetic model appears to be suitable at least in the domain of moderate degrees of conversion and allows the extent of PDCPD degradation to be predicted with time, temperature and external oxygen pressure as input parameters. The case of stabilized PDCPD should now be addressed to get closer to practical cases $[4,5,6,29]$.

\section{Acknowledgements}

Agence Nationale de la Recherche is gratefully acknowledged for having funded this study (Project VRPOM - Vieillissement des Réseaux Polymérisés par Métathèse - 2016-2019).

The French Region Ile-de-France SESAME Program is acknowledged for financial support (700 MHz spectrometer).

\section{APPENDIX 1}

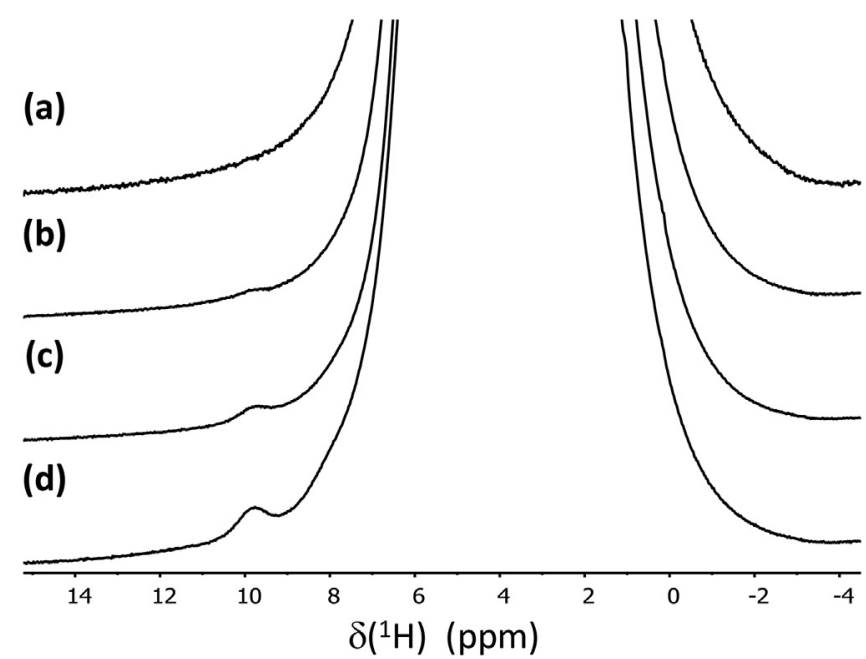

Fig. A1. Zoom of the one-pulse ${ }^{1} \mathrm{H}$ MAS NMR spectra of purified, unaged and aged PDCDP, recorded at a ${ }^{1} \mathrm{H}$ Larmor frequency $\nu_{0}$ of $700 \mathrm{MHz}$ and a MAS frequency $\nu_{\mathrm{r}}$ of $50 \mathrm{kHz}$. Ageing was carried out at $50{ }^{\circ} \mathrm{C}$, under air, for: (a) $0 \mathrm{~h}$, (b) $4 \mathrm{~h}$, (c) $7 \mathrm{~h}$ and (d) $25 \mathrm{~h}$.

\section{APPENDIX 2}

$$
\begin{aligned}
& \frac{d[\mathrm{POOH}]}{d t}=-k_{1 u}[\mathrm{POOH}]-2 k_{1 b}[\mathrm{POOH}]^{2}+k_{3}\left[\mathrm{POO}^{\circ}\right][\mathrm{PH}] \\
& \quad+k_{5}\left(1-\gamma_{5}\right)\left[\mathrm{P}^{\circ}\right]\left[\mathrm{POO}^{\circ}\right] \\
& \frac{d\left[\mathrm{P}^{\circ}\right]}{d t}=2 k_{1 u}[\mathrm{POOH}]+k_{1 b}[\mathrm{POOH}]^{2}-k_{2}\left[\mathrm{P}^{\circ}\right]\left[\mathrm{O}_{2}\right]+k_{3}\left[\mathrm{POO}^{\circ}\right][\mathrm{PH}] \\
& \quad-2 k_{4}\left[\mathrm{P}^{\circ}\right]^{2}-k_{5}\left[\mathrm{P}^{\circ}\right]\left[\mathrm{POO}^{\circ}\right]+k_{a 2}\left[\mathrm{POO}^{\circ}\right][\mathrm{C}=\mathrm{C}] \\
& \frac{d\left[\mathrm{POO}^{\circ}\right]}{d t}=k_{1 b}[\mathrm{POOH}]^{2}+k_{2}\left[\mathrm{P}^{\circ}\right]\left[\mathrm{O}_{2}\right]-k_{3}\left[\mathrm{POO}^{\circ}\right][\mathrm{PH}]-k_{5}\left[\mathrm{P}^{\circ}\right]\left[\mathrm{POO}^{\circ}\right] \\
& \quad-2 k_{6}\left[\mathrm{POO}^{\circ}\right]^{2}-k_{a 2}\left[\mathrm{POO}^{\circ}\right][\mathrm{C}=\mathrm{C}]
\end{aligned}
$$

$$
\begin{aligned}
& \frac{d[P=O]}{d t}=\gamma_{1 u} k_{1 u}[\mathrm{POOH}]+\gamma_{1 b} k_{1 b}[\mathrm{POOH}]^{2}+\gamma_{1} k_{a 2}\left[\mathrm{POO}^{\circ}\right][\mathrm{C}=\mathrm{C}] \\
& \quad+k_{6}\left[\mathrm{POO}^{\circ}\right]^{2}
\end{aligned}
$$$$
\begin{aligned}
& \frac{d[C=C]}{d t}=-k_{a 1}\left[P^{\circ}\right][C=C]-k_{a 2}\left[P O O^{\circ}\right][C=C]+\left(1-\gamma_{4}\right) k_{4}\left[P^{\circ}\right]^{2} \\
& \quad+\left(1-\gamma_{5}\right) k_{5}\left[P^{\circ}\right]\left[P O O^{\circ}\right]
\end{aligned}
$$$$
\begin{aligned}
& \frac{d[P H]}{d t}=-\left(2-\gamma_{1}\right) k_{1 u}[P O O H]-\left(1-\gamma_{1}\right) k_{1 b}[P O O H]^{2} \\
& \quad-k_{3}\left[P O O^{\circ}\right][P H]-2 k_{a 1}\left[P^{\circ}\right][C=C]-2 k_{a 2}\left[P O O^{\circ}\right][C=C] \\
& \quad+\left(1-\gamma_{4}\right) k_{4}\left[P^{\circ}\right]^{2}
\end{aligned}
$$

\section{References}

[1] Y. Chauvin, Olefin metathesis: the early days (Nobel lecture), Angew. Chem. Int. Ed. 45 (2006) 3740-3747, https://doi.org/10.1002/anie.200601234.

[2] R.H. Grubbs, Olefin-metathesis catalysts for the preparation of molecules and materials (Nobel lecture), Angew. Chem. Int. Ed. 45 (2006) 3760-3765, https://doi.org/10.1002/anie.200600680.

[3] J.-P. Pascault, H. Sautereau, J. Verdu, R.J. Williams, Thermosetting Polymers, Marcel Dekker, New York, 2002.

[4] Y. Hu, Y. Zhang, S. Nutt, Thermal oxidation aging of polydicyclopentadiene and composites, Polym. Compos. 39 (2018) 1742-1751.

[5] T.R. Long, R.M. Elder, E.D. Bain, K.A. Masser, T.W. Sirk, H.Y. Jian, D.B. Knorr, J.L. Lenhart, Influence of molecular weight between crosslinks on the mechanical properties of polymers formed via ring-opening metathesis, Soft Matter 14 (2018) 3344-3360.

[6] P.Y. Le Gac, D. Choqueuse, M. Paris, G. Recher, C. Zimmer, D. Melot, Durability of polydicyclopentadiene under high temperature, high pressure and seawater (offshore oil production conditions), Polym. Degrad. Stabil. 98 (2013) 809-817, https://doi.org/10.1016/j.polymdegradstab.2012.12.023.

[7] M. Coquillat, J. Verdu, X. Colin, L. Audouin, R. Nevière, Thermal oxidation of polybutadiene. Part 2: mechanistic and kinetic schemes for additive-free noncrosslinked polybutadiene, Polym. Degrad. Stabil. 92 (2007) 1334-1342, https://doi.org/10.1016/j.polymdegradstab.2007.03.019.

[8] E. Richaud, P.Y. Le Gac, J. Verdu, Thermooxidative aging of polydicyclopentadiene in glassy state, Polym. Degrad. Stabil. 102 (2014) 95-104, https://doi.org/10.1016/j.polymdegradstab.2014.01.036.

[9] E. Richaud, F. Farcas, P. Bartoloméo, B. Fayolle, L. Audouin, J. Verdu, Effect of oxygen pressure on the oxidation kinetics of unstabilised polypropylene, Polym. Degrad. Stabil. 91 (2006) 398-405, https://doi.org/10.1016/ j.polymdegradstab.2005.04.043.

[10] X. Colin, L. Audouin, J. Verdu, Determination of thermal oxidation rate constants by an inverse method. Application to polyethylene, Polym. Degrad. Stabil. $86 \quad$ (2004) 309-321, https://doi.org/10.1016/ j.polymdegradstab.2004.04.022

[11] M. Coquillat, J. Verdu, X. Colin, L. Audouin, R. Nevière, Thermal oxidation of polybutadiene. Part 1: effect of temperature, oxygen pressure and sample thickness on the thermal oxidation of hydroxyl-terminated polybutadiene, Polym. Degrad. Stabil. 92 (2007) 1326-1333, https://doi.org/10.1016/ j.polymdegradstab.2007.03.020.

[12] P.Y. Le Gac, G. Roux, J. Verdu, P. Davies, B. Fayolle, Oxidation of unvulcanized, unstabilized polychloroprene: a kinetic study, Polym. Degrad. Stabil. 109 (2014) 175-183, https://doi.org/10.1016/j.polymdegradstab.2014.06.019.

[13] V. Defauchy, P.Y. Le Gac, A. Guinault, J. Verdu, G. Recher, R. Drozdzak, E. Richaud, Kinetic analysis of polydicyclopentadiene oxidation, Polym. Degrad. Stabil. 142 (2017) 169-177, https://doi.org/10.1016/ j.polymdegradstab.2017.06.005.

[14] E. Richaud, F. Farcas, B. Fayolle, L. Audouin, J. Verdu, Hydroperoxide titration by DSC in thermally oxidized polypropylene, Polym. Test. 25 (2006) 829-838, https://doi.org/10.1016/j.polymertesting.2006.04.010.

[15] Y. Ouldmetidji, L. Gonon, S. Commereuc, V. Verney, A differential scanning calorimetry method to study polymer photoperoxidation, Polym. Test. 20 (2001) 765-768, https://doi.org/10.1016/S0142-9418(01)00024-1.

[16] C.L. McGann, G.C. Daniels, S.L. Giles, R.B. Balow, J.L. Miranda-Zayas, J.G. Lundin, J.H. Wynne, Air activated self-decontaminating polydicyclopentadiene PolyHIPE foams for rapid decontamination of chemical warfare agents, Macromol. Rapid Commun. 39 (2018) 1800194.

[17] M.J. Abadie, M. Dimonie, C. Couve, V. Dragutan, New catalysts for linear polydicyclopentadiene synthesis, Eur. Polym. J. 36 (2000) 1213-1219, https:// doi.org/10.1016/S0014-3057(99)00185-8.

[18] J. Villarreal, J. Laane, S. Bush, W. Harris, Vibrational spectra and normal coordinate analysis for cyclopentene, cyclopentene-1-d1, cyclopentene-1, 2, 3, 
3-d4 and cyclopentene-d8, Spectrochim. Acta Part A Mol. Spectrosc. 35 (1979) 331-338, https://doi.org/10.1016/0584-8539(79)80188-9.

[19] D. Nava, T.R. de Parada, E. González, N. Boscàn, C. De La Cruz, An infrared spectroscopic comparison of cis- and trans- $\mathrm{CH}=\mathrm{CH}$ and vinyl $\mathrm{CH}=\mathrm{CH} 2$ group frequencies of some hexenes, heptenes, and stereospecific and nonstereospecific polybutadienes, Spectrochim. Acta. A. Mol. Biomol. Spectrosc 52 (1996) 1201-1210, https://doi.org/10.1016/0584-8539(96)01676-5.

[20] D. Lin-Vien, N.B. Colthup, W.G. Fateley, J.G. Grasselli, CHAPTER 6 - alkenes, in: Handb. Infrared Raman Charact. Freq. Org. Mol., Academic Press, San Diego, 1991, pp. 73-94, https://doi.org/10.1016/B978-0-08-057116-4.50012-2.

[21] J.G. Calvert, J.N. Pitts, Photochemistry, New York, 1966.

[22] H.L. McMurry, V. Thornton, Correlation of infrared spectra, Anal. Chem. 24 (1952) 318-334, https://doi.org/10.1021/ac60062a018.

[23] R.M. Elder, J.W. Andzelm, T.W. Sirk, A molecular simulation study of the glass transition of cross-linked poly (dicyclopentadiene) networks, Chem. Phys. Lett. 637 (2015) 103-109.

[24] D.B. Knorr Jr., K.A. Masser, R.M. Elder, T.W. Sirk, M.D. Hindenlang, H.Y. Jian, A.D. Richardson, S.E. Boyd, W.A. Spurgeon, J.L. Lenhart, Overcoming the structural versus energy dissipation trade-off in highly crosslinked polyme networks: ultrahigh strain rate response in polydicyclopentadiene, Compos. Sci. Technol. 114 (2015) 17-25.

[25] G.A. Russell, Deuterium-isotope effects in the autoxidation of aralkyl hydrocarbons. Mechanism of the interaction of PEroxy radicals ${ }^{1}$, J. Am. Chem. Soc. 79 (1957) 3871-3877, https://doi.org/10.1021/ja01571a068.

[26] J.A. Howard, K.U. Ingold, Self-reaction of sec-butylperoxy radicals. Confirmation of the Russell mechanism, J. Am. Chem. Soc. 90 (1968) 1056-1058, https://doi.org/10.1021/ja01006a037.

[27] A.V. Tobolsky, D.J. Metz, R.B. Mesrobian, Low temperature autoxidation of hydrocarbons: the phenomenon of maximum Rates1,2, J. Am. Chem. Soc. 72 (1950) 1942-1952, https://doi.org/10.1021/ja01161a023.

[28] X. Colin, L. Audouin, J. Verdu, Kinetic modelling of the thermal oxidation of polyisoprene elastomers. Part 1: unvulcanized unstabilized polyisoprene, Polym. Degrad. Stabil. 92 (2007) 886-897, https://doi.org/10.1016/ j.polymdegradstab.2007.01.017.

[29] J. Huang Thermo Oxidation of Polydicyclopentadiene: Determination the Initiation Rate Constants and Termination Rate Constants of Kinetic Model 2018. https://www.nist.gov/news-events/events/2018/03/service-lifeprediction-polymeric-materials-reaching-new-heights.

[30] E.T. Denisov, I.B. Afanas'ev, Oxidation and Antioxidants in Organic Chemistry and Biology, Taylor \& Francis, 2005.

[31] K.T. Gillen, J. Wise, R.L. Clough, General solution for the basic autoxidation scheme, Polym. Degrad. Stabil. 47 (1995) 149-161, https://doi.org/10.1016/ 0141-3910(94)00105-H. 